\title{
Auditory Function Testing for Types of Dementia: Systematic Reviews and Meta-Analysis
}

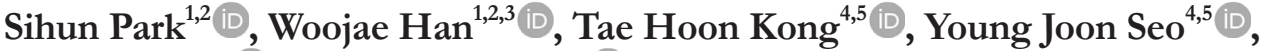 \\ Jaehyun Han $^{6}$ iD, and Tae Hui Kim ${ }^{6}$ iD \\ ${ }^{1}$ Laboratory of Hearing and Technology, College of Natural Sciences, Hallym University, Chuncheon; and \\ ${ }^{2}$ Division of Speech Pathology and Audiology, College of Natural Sciences, Hallym University, Chuncheon; and \\ ${ }^{3}$ Research Institute of Audiology and Speech Pathology, College of Natural Sciences, Hallym University, Chuncheon; and \\ ${ }^{4}$ Department of Otorhinolaryngology-Head and Neck Surgery, Yonsei University Wonju College of Medicine, Wonju; and \\ ${ }^{5}$ Research Institute of Hearing Enhancement, Wonju; and \\ ${ }^{6}$ Department of Psychiatry, Yonsei University Wonju College of Medicine, Wonju, Korea
}

\author{
치매 환자를 위한 청각 검사의 체계적 문헌 고찰 및 메타 분석

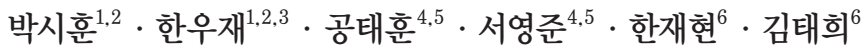 \\ 한림대학교 자연과학대학 HearT 실험실, ${ }^{1}$ 언어청각학부, ${ }^{2}$ 청각언어연구소, ${ }^{3}$ \\ 연세대학교 원주의과대학 이비인후과학교실, ${ }^{4}$ 청각재활 연구소, ${ }^{5}$ 연세대학교 원주의과대학 정신과학교실 ${ }^{6}$
}

\author{
Received July 31,2020 \\ Revised August 26, 2020 \\ Accepted September 11, 2020 \\ Address for correspondence \\ Woojae Han, PhD \\ Division of Speech Pathology \\ and Audiology, \\ College of Natural Sciences, \\ Hallym University \\ 8603 Natural Science Building, \\ 1 Hallym Daehak-gil, \\ Chuncheon 24252, Korea \\ Tel $+82-33-248-2216$ \\ Fax $+82-33-256-3420$ \\ E-mail woojaehan@hallym.ac.kr
}

It is acknowledged that there is a negative relationship between dementia and auditory function in older adults. This study conducted a systematic review and meta-analysis based on the data of audiologic testings from patients with neurodegenerative diseases in terms of auditory eventrelated potentials and central auditory processing tests, while focusing on Alzheimer's disease (AD), dementia with Lewy bodies (DLB), and Parkinson's disease dementia (PDD). A total of 34765 articles were retrieved from the seven electronic databases. After being screened by Participants, Index test, Control, Outcomes, Study design (PICOS) criteria, 129 articles for AD were included and then 72 articles were applied to the meta-analysis. However, five and six articles were systematically reviewed for the auditory functions of DLB and PDD, respectively, due to a small number of articles. The results of meta-analysis showed a significant difference between patients with AD and age-matched normal subjects, for N200 and P300 latency, P300 amplitude, and the behavioral central auditory processing tests, although there was a high heterogeneity. On the other hand, the systematic review indicated that the results of mismatch negativity test might distinguish auditory performance of DLB patients from that of PDD. Furthermore, for P300 amplitude, anterior to posterior distribution of brain resulted in meaningful difference of auditory function between AD and DLB patients. In sum, current review study suggests that lesion and degree of auditory (dys)function may be different depending on the type of dementia, although future research should be followed.

Korean J Otorhinolaryngol-Head Neck Surg 2021;64(2):47-69

Key Words Alzheimer's disease · Auditory event-related potentials ·

Central auditory processing · Dementia with Lewy bodies ·

Parkinson's disease dementia.

This is an Open Access article distributed under the terms of the Creative Commons Attribution Non-Commercial License (https://creativecommons.org/licenses/by-nc/4.0) which permits unrestricted non-commercial use, distribution, and reproduction in any medium, provided the original work is properly cited. 


\section{서 론}

최근 청각 기능의 결손이 치매의 위험 요인으로 주목받게 되면서 ${ }^{1)}$ 청각 검사를 치매 진단에 활용하고자 하는 일련의 연구들이 활발히 진행되고 있다. ${ }^{2}$ 구체적으로, 알츠하이머병 (Alzheimer's disease, $\mathrm{AD}$ ) 환자에게 청성유발전위(auditory event-related potentials)의 여러 요소들 중 N200과 P300 측정 파형의 잠복기(latency)와 P300 반응의 진폭(amplitude) 을 분석한 결과들을 바탕으로 메타 분석을 실시한 연구에서 는 정상 인지 기능의 대조군과 비교 시 $\mathrm{AD}$ 환자의 N200과 $\mathrm{P} 300$ 잠복기가 유의하게 지연되었고 ${ }^{3,4} \mathrm{P} 300$ 의 진폭은 유의 하게 감소하였다.5) 이러한 선행 연구들은 임상 적용을 위한 기초적 자료제공은 가능하지만, 대부분의 개별 연구에서 한 계점으로 보고하였듯이 특정 요소의 측정 반응에만 초점을 두어 아쉽게도 청각적 정보처리 및 인지 과정을 종합적으로 파악하지 못하였다. ${ }^{6}$ 즉, 청각 기관을 통한 선택적 주의력 $\left(\mathrm{se}^{-}\right.$ lective attention)과 관련 있는 N100, 소리의 음향적 특성 분 석의 기초 능력(elementary feature analysis)과 연관된 N200, 청각 정보 처리 및 청각적 인지 기능을 측정하는 P300 등 여 러 요소들의 결과들을 근거로 중추청각기관의 경로를 전반 적으로 확인하고 치매 환자들의 청각 처리 능력을 종합적으 로 이해할 필요가 있다.

대표적으로 알려진 퇴행성 뇌 질환은 $\mathrm{AD}$, 파킨슨병(Parkinson's disease, PD), 루이소체치매(dementia with Lewy bodies, DLB), 파킨슨병치매(Parkinson's disease dementia, $\mathrm{PDD})$ 등으로, 공통적으로 변형된 단백질의 비정상적 침착으 로 인한 변형단백질환(proteinopathy)을 특징으로 한다. 그러 나 퇴행성 뇌질환으로 인한 치매는 한 종류의 변형 단백질로 야기된 문제보다는 여러 변형 단백질들의 복합적인 영향을 받게 되기에, 유형이 다른 치매들 간에도 증상이 비슷하게 나타나는 경우가 흔하다. ${ }^{8}$ 예를 들어, 사후 부검 연구에서는 일부 DLB 환자에서 베타-아밀로이드가 검출되기도 하고, 역으로 후기 $\mathrm{AD}$ 환자에서는 알파-시누클레인의 변형된 형 태인 루이소체(Lewy body, LB)가 관찰되기도 한다.") 특히, $\mathrm{AD}, \mathrm{DLB}, \mathrm{PDD}$ 는 그 형태가 많이 중복되기에 진단에 어려 움이 있으며, 이들의 관계를 밝히기 위한 연구가 계속해서 진 행되고 있다. ${ }^{8)}$ 1995년에 $\mathrm{DLB}$ 는 $\mathrm{AD}$ 와 PDD로 부터 임상병 리학적으로 구분이 되었으나, 2014년까지도 DLB를 다른 유 형의 치매로 오진하는 경우가 많아 최근에도 계속해서 진단 기준이 수정되고 있다.10)

Hardy 등 ${ }^{11)}$ 은 치매의 유형에 따른 피질의 구조적 또는 위치 적 손상이 청각 기능 저하에 정도의 차별적 영향을 줄 수 있 다고 보고하였다. 즉, 치매는 청각 기능이 비교적 잘 보존되는
유형이 있는 반면, 심각한 청각 기능 손상을 보이는 치매의 유형이 있다. 청각적 기능 손상과 관련된 뇌 네트워크의 병리 학적 위치를 구분해보면, $\mathrm{AD}$ 환자의 경우 후측대상피질(posterior cingulate cortex), 쐐기앞소엽(precuneus), 측두두정부 (temporo-parietal cortices)로, ${ }^{11}$ 해당 위치의 손상은 복잡한 음향 환경에서 음원의 위치를 파악하는 능력이 저하되며 ${ }^{22}$ 청각장면분석(auditory scene analysis)이 어려워지고 ${ }^{13)}$ 소리 에 대한 민감도가 증가하게 된다. ${ }^{14)}$ 반면, $\mathrm{DLB}$ 와 $\mathrm{PDD}$ 의 의 병리학적 위치는 피질-피질하 회로(cortico-subcortical circuits)로써 해당 부위의 손상은 청각적 자극에 대한 탐지 및 분석이 어렵고 청각장면분석 능력이 저하되어 ${ }^{15,16)}$ 궁극적으 로는 청각적 주의력과 작업 기억력에 부정적 영향을 끼치게 된다. ${ }^{17)}$ 이러한 다양한 치매 유형들의 청각 기능의 차이에 따 라 청각 검사를 환자들에게 적용하여 그 유형을 세분화하고 자 하는 연구들이 시도되고 있으나, ${ }^{18-20)}$ 실제 임상 현장의 적 용까지는 많은 검증이 필요한 상황이다.

치매 환자의 청각 검사 결과들을 바탕으로 실시한 기존의 메타 분석 연구는 다음과 같은 한계점을 갖는다. 청성유발전 위 검사들 중 특정 요소만의 메타 분석 결과를 제공했고, 1995년 이전 문헌을 포함하여 치매 유형에 따른 연구 대상 자를 구분하지 못하였을 가능성이 높고, 치매 환자의 주관적 측정 결과에 대한 메타 분석 문헌의 부재 등이다. 따라서 본 종설 논문에서는 비교적 비슷한 증상으로 진단이 까다로운 $\mathrm{AD}, \mathrm{DLB}, \mathrm{PDD}$ 환자들에게 객관적 및 주관적으로 실시한 청각 검사들을 적용한 문헌들을 검색하고 세분화하여 분류 한 후 메타 분석을 실시하여 현재 치매 환자들의 청각 결과 들을 종합적으로 정리하고자 한다.

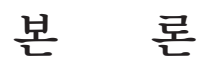

\section{체계적 문헌 검색의 전략과 선정}

문헌 선정, 데이터 추출과 분석, 문헌의 포함과 제외 방법은 Participants, Index test, Control, Outcomes, Study design (PICOS) 기준을 적용하였다. ${ }^{21)}$ 즉, 문헌은 PICOS 기준에 의 거하여 선정 및 분류되었으며, 구체적인 체계적 문헌 고찰의 과정은 PRISMA 2015 Flow Diagram을 참고하여 작성하였 다. ${ }^{22)}$ 체계적 문헌 고찰의 모든 과정은 두 명의 저자에 의해 독립적으로 평가되었다. 추출된 데이터 및 문헌이 두 저자에 의해 합의가 이루어지지 않은 경우에는 문헌을 재검토하여 논의하였다. 본 연구에 적용한 PICOS 기준은 Table 1 에 기술 하였다. 
Table 1. Participants, Index test, Control, Outcomes, and Study designs (PICOS) strategy used in the study

PICOS

Participants

Index test

Control

Outcomes

Study design

\section{Contents}

Clearly mentioned as an Alzheimer disease or Parkinson's disease dementia or Dementia with Lewy bodies All the audiological testing (i.e., Speech perception, Speech recognition, PTA, OAE, ABR, AMLR, ALR, etc.) Comparison with a control group or repeated measures Outcome measure(s) related to audiological testing results Randomized controlled trials, non-randomized controlled trials, cohort studies (with a control comparison), and repeated measures (pre- and post- comparisons)

PTA: puretone audiometry, OAE: otoacoustic emission, ABR: auditory brainstem response, AMLR: auditory middle latency response, ALR: auditory late latency response

\section{문헌 발견(Identification)}

본 종설에서는 $\mathrm{AD}, \mathrm{DLB}, \mathrm{PDD}$ 환자군을 대상으로 청각 검사를 적용한 연구만을 선정하고 수집하였다. 연구 목적에 따른 구체적인 문헌 선정을 위해, 7개의 전문 학술 전자 데이 터베이스인 Pubmed, Embase, Medline, Web of science, SciELO, Scopus, Cochrane Library에서 문헌을 검색하였다. 검색어는 의학주제명표목(Medical Subject Headings, MeSH) 용어 및 선행 문헌에서 자주 표현된 용어에서 확인하였다: 'Alzheimer disease(AD)' OR 'Parkinson's disease Dementia (PDD)' OR 'Dementia with Lewy bodies(DLB)' OR 'Proteinopathy' OR 'Lewy' OR 'Dementia' OR 'Alzheimer' AND 'Auditory function' OR 'Biomarker' OR 'Auditory perception' OR 'Speech perception' OR 'Electroencephalography (EEG)' OR 'Speech recognition' OR 'Evoked potential' OR 'Event-related potential' OR 'Electrophysiology' OR 'Auditory stimulation' OR 'Behavioral' OR 'Objective' AND 'Pure tone audiometry(PTA)' OR 'Mismatch negativity(MMN)' OR 'P300(P3)' OR 'N100(N1)' OR 'N200(N2)' OR 'P100(P1)' OR 'N400(N4)' OR 'Auditory brainstem response(ABR)' OR 'Otoacoustic emission(OAE)' OR 'Auditory steady-state response(ASSR)' OR 'Auditory middle latency response(AMLR)'.

출간기간에 따른 문헌들의 선정기준은 The Consortium on Dementia with Lewy bodies에서 DLB의 진단기준을 설정 하고 별개의 임상 증후군으로 인정되어 $\mathrm{DLB}$ 가 $\mathrm{AD}$ 및 $\mathrm{PDD}$ 와의 임상 병리학적 분리가 구체화된 1995년 1월을 기점으 로 하였다. ${ }^{23)}$ 즉, 1995년 1월 2020년 5월까지의 문헌이 본 논 문에 포함되었다. 본 종설에서는 연구논문만을 포함하여 서 적, 종설, 학회 초록, 메타 분석 연구는 제외되었으며, 경도인 지장애 및 동물 연구 또한 제외시켰다.

\section{문헌 선별(Screening)}

7개의 전문 학술 전자 데이터베이스를 사용하여 34765 개의 문헌이 검색되어 스크리닝 단계에 포함되었다(Fig. 1, Iden- tification level). 그 중 중복되는 문헌(n=6762)을 제거하여 28003개의 문헌이 선별되었고, 문헌의 초록을 PICOS 기준 에 의거하여 두 명의 저자에 의해 독립적으로 검토되었다. 결 과적으로 19006 개의 문헌이 제거되어 총 8997 개의 문헌이 선정기준 평가 단계에 포함되었다(Fig. 1, Screening level). 즉, 선정기준 평가 단계에 포함된 문헌들은 PICOS 기준을 충 족하거나, 초록의 내용만으로는 평가하기 어려운 경우를 모 두 포함하였다.

\section{선정 기준(Eligibility)의 검토 및 최종 선정(Inclusion)}

다양한 이유로 PICOS 기준을 충족하지 못한 8860개의 문 헌이 제거되어, 결과적으로 137 개의 문헌이 선정기준에 만족 하였다(Fig. 1, Eligibility level). 그 중 129개의 문헌이 AD 환 자군을 포함하였으며, $\mathrm{DLB}$ 와 PDD 환자군을 포함한 문헌은 각각 5 개와 6 개였다(Fig. 1, Included level). 해당 문헌에서 주로 사용된 청각 검사들은 청성유발전위 검사, 중추청각검 사, 청각단어회상검사, 순음청력검사, 단어인지검사, 문장인 지검사 등이다.

$\mathrm{AD}$ 환자군을 포함한 개별 문헌에서 데이터를 추출하는 과정 중 표준편차 데이터 누락(5/26), 구체적인 수치의 누락 (11/26), 검사 도구간의 상관 분석 결과만을 제시하여 고유의 데이터 확인이 불가(3/26), 연구대상자 간의 혼재된 결과 제 시(3/26), 전체적인 데이터만을 제시한(4/26), 총 26개의 문헌 이 추가적으로 제거되었다. 데이터의 추출 과정에서 선정기 준을 만족하였으나, 포함된 문헌 수가 6개 이하로 매우 적어 메타 분석에 포함되지 못한 검사는 P100 진폭, P100 잠복기, N100 진폭, P200 진폭, N200 진폭, mismatch negativity $(\mathrm{MMN})$ 잠복기, $\mathrm{MMN}$ 진폭, $\mathrm{Pa} / \mathrm{Pb}$, puretone audiometry (PTA), auditory brainstem response(ABR)였으며, 총 31건 의 문헌이 이에 포함되었다. 따라서, 메타 분석을 실시하기 위 해 최종 72 개의 문헌이 포함되었다(Fig. 1, Analysis level).

\section{$\mathrm{AD}$ 환자의 청각 기능에 관한 메타 분석}

메타 분석에 사용된 문헌은 $\mathrm{AD}$ 환자의 청각 검사 결과, 실 


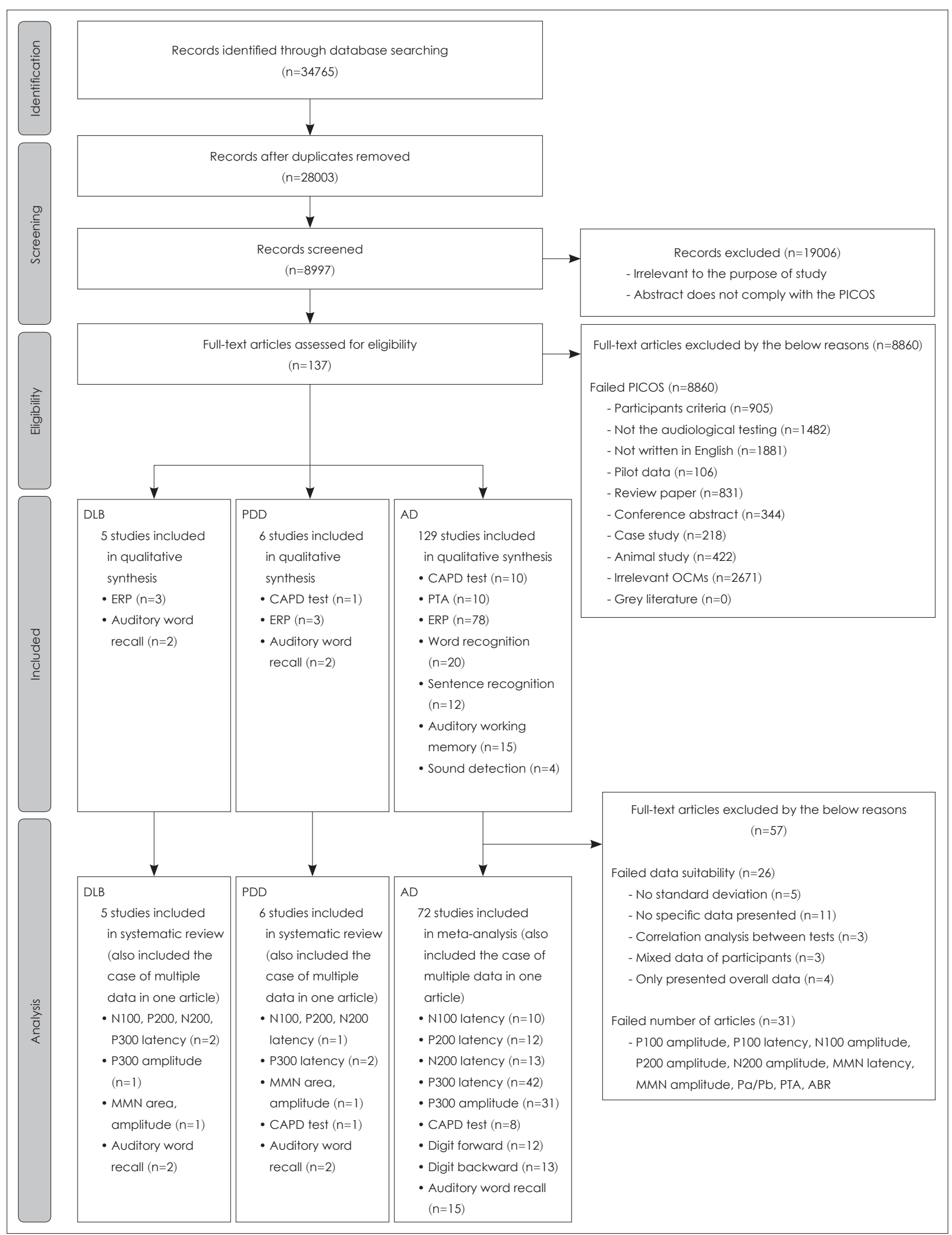

Fig. 1. Flowchart of the study identification, eligibility, and inclusion process based on the Preferred Reporting Items for Systematic Reviews and Meta Analyses (PRISMA) criteria. PICOS: Participants, Index test, Control, Outcomes, Study design, DLB: dementia with Lewy bodies, PDD: Parkinson's disease dementia, AD: Alzheimer's disease, ERP: event-related potential, CAPD: central auditory processing disorder, PTA: puretone audiometry, OCM: outcome, MMN: mismatch negativity, ABR: auditory brainstem response. 
험군과 동일 연령의 대조군 결과, 적절한 결과 측정 데이터를 모두 포함하였다. 효과 크기의 계산은 실험군과 대조군의 평 균, 표준편차, 연구대상자의 수를 사용하였고, 청성유발전위 반응 및 청각적 수행력을 확인한 실험 결과임에도 대부분의 연구는 검사 설정 및 검사 도구의 다양성으로 인해 표준화된 평균 차이(standardized mean difference, SMD)로 효과 크 기가 계산되었다. ${ }^{24)}$ 모든 효과 크기는 $95 \%$ 의 신뢰구간을 갖 는 확률효과모델(random effect model)을 사용하였으며, 하 위군 분석은 하위군 간의 혼합 효과 Q검정을 사용하여 효과 크기를 비교하였다. ${ }^{25)}$ 하나의 문헌에서 여러개의 데이터가 추 출될 경우 각각의 데이터는 개별적인 데이터로 간주하여 분 석을 실시하였다. 예를들어, 하나의 문헌에서 특정 요소의 반 응을 다양한 전극위치에서 확인할 때 각각의 결과는 개별 데 이터로 간주된다. 전극위치는 같지만 자극음에 따른 반응을 측정한 경우에도 자극음에 따른 각각의 반응 결과가 개별 데 이터로 간주된다. 깔때기 도표(funnel plot)와 Egger's 회귀 비대칭 분석은 출판편향(publication bias)을 확인하기 위해 사용되었다. ${ }^{26)}$ 메타 분석을 위해 Comprehensive MetaAnalysis (Ver. 3, Biostat Inc., Englewood, NJ, USA) 프로 그램을 사용하였다.

본 메타 분석에 사용된 72 개의 문헌들의 데이터를 바탕으
로 Fig. 2 를 제작하여 $\mathrm{AD}$ 환자군과 대조군의 각 검사별 차 이값을 가시화하였다. 메타 분석 및 Egger's 회귀 비대칭 분 석의 결과는 Table 2에 정리하였다. 대부분의 메타 분석 결과 에서 높은 이질성 $\left(\mathrm{I}^{2} \geq 75 \%\right)$ 이 확인되어 청성유발전위 검사는 측정 전극과 자극음의 종류를 구분하여 하위군 분석을 실시 하였다. 또한, 주관적 청각검사에서는 검사 도구의 종류, 검 사의 특성을 고려하여 지연시간, 측정한 귀에 대해 하위군 분 석을 실시하였다. 메타 분석의 숲 그림(forest plot)은 부록 (Appendix 1, 2, and 3)에 제시하였다.

\section{객관적 청성유발전위 검사}

\section{N100 latency}

$\mathrm{N} 100$ 잠복기의 메타 분석은 12 개의 문헌에서 총 15 개의 데 이터로 실시하였다. 15 개의 데이터 평균은 다른 측정 요소들 과 함께 Fig. 2A에 제시하였다(AD mean: $107.15 \pm 10.74 \mathrm{ms,}$ control mean: $107.00 \pm 14.59 \mathrm{~ms}) . \mathrm{AD}$ 환자군과 대조군의 $\mathrm{N} 100$ 잠복기를 비교한 메타 분석 결과는 유의한 차이를 보 이지 않았으며 $[S M D=0.672,95 \%$ confidence interval $(\mathrm{CI})=$ -0.051 to $1.395, p=0.069]$, 높은 이질성이 확인되었다 $\left(\mathrm{I}^{2}=\right.$ 94.15\%). Egger's 회귀 비대칭 분석시 출판편향이 존재함을

Table 2. Summary of meta-analysis results for 72 articles in Alzheimer's disease and Egger's regression

\begin{tabular}{|c|c|c|c|c|c|c|c|c|c|}
\hline \multirow[b]{2}{*}{ Characteristic } & \multirow[b]{2}{*}{ Studies } & \multicolumn{4}{|c|}{ Effect size and $95 \% \mathrm{Cl}$} & \multicolumn{4}{|c|}{ Homogeneity tests } \\
\hline & & $\begin{array}{l}\text { Standard } \\
\text { means diff }\end{array}$ & $\begin{array}{c}\text { Lower } \\
\text { limit }\end{array}$ & $\begin{array}{l}\text { Upper } \\
\text { limit }\end{array}$ & $p$ & Q & $\mathrm{df}(\mathrm{Q})$ & $p$ & $1^{2}$ \\
\hline N100 latency & 12 & 0.672 & -0.051 & 1.395 & 0.069 & 153.733 & 9 & $<0.001$ & 94.15 \\
\hline P200 latency & 10 & 0.129 & -0.131 & 0.389 & 0.331 & 28.448 & 11 & 0.003 & 61.33 \\
\hline N200 latency & 13 & 1.144 & 0.475 & 1.813 & 0.001 & 164.962 & 12 & $<0.001$ & 92.73 \\
\hline P300 latency & 42 & 1.220 & 0.936 & 1.504 & $<0.001$ & 482.119 & 41 & $<0.001$ & 91.50 \\
\hline P300 amplitude & 31 & -0.595 & -0.907 & -0.284 & $<0.001$ & 358.502 & 30 & $<0.001$ & 91.63 \\
\hline CAPD & 8 & -1.299 & -1.512 & -1.086 & $<0.001$ & 8.091 & 7 & 0.325 & 13.49 \\
\hline Digit forward & 12 & -0.659 & -0.918 & -0.399 & $<0.001$ & 19.162 & 11 & 0.058 & 42.59 \\
\hline Digit backward & 13 & -0.901 & -1.179 & -0.624 & $<0.001$ & 24.852 & 12 & 0.016 & 51.71 \\
\hline Auditory word recall & 15 & -2.308 & -2.767 & -1.848 & $<0.001$ & 339.334 & 14 & $<0.001$ & 95.87 \\
\hline Egger's regression & & Intercept & $\begin{array}{c}\text { Standard } \\
\text { error }\end{array}$ & $\begin{array}{c}\text { Lower } \\
\text { limit }\end{array}$ & $\begin{array}{l}\text { Upper } \\
\text { limit }\end{array}$ & $\begin{array}{c}p \\
(1-\text { tailed })\end{array}$ & $\begin{array}{c}\mathrm{p} \\
(2 \text {-tailed })\end{array}$ & df & t-value \\
\hline N100 latency & & 12.199 & 3.047 & 5.617 & 18.781 & 0.001 & 0.002 & 13 & 4.004 \\
\hline P200 latency & & -0.678 & 2.423 & -5.912 & 4.556 & 0.392 & 0.784 & 13 & 0.280 \\
\hline N200 latency & & 6.772 & 2.586 & 1.226 & 12.319 & 0.010 & 0.020 & 14 & 2.619 \\
\hline P300 latency & & 6.089 & 1.067 & 3.959 & 8.219 & $<0.001$ & $<0.001$ & 67 & 5.706 \\
\hline P300 amplitude & & -6.934 & 1.576 & -10.093 & -3.775 & $<0.001$ & $<0.001$ & 54 & 4.401 \\
\hline CAPD & & -3.461 & 0.700 & -4.932 & -1.990 & $<0.001$ & $<0.001$ & 18 & 4.943 \\
\hline Digit forward & & -2.997 & 2.715 & -9.047 & 3.054 & 0.148 & 0.296 & 10 & 1.104 \\
\hline Digit backward & & -4.315 & 2.510 & -9.840 & 1.210 & 0.057 & 0.114 & 11 & 1.719 \\
\hline Auditory word recall & & 2.671 & 1.538 & -0.528 & 5.870 & 0.048 & 0.097 & 21 & 1.736 \\
\hline
\end{tabular}

Cl: confidence interval, CAPD: Central auditory processing disorder 

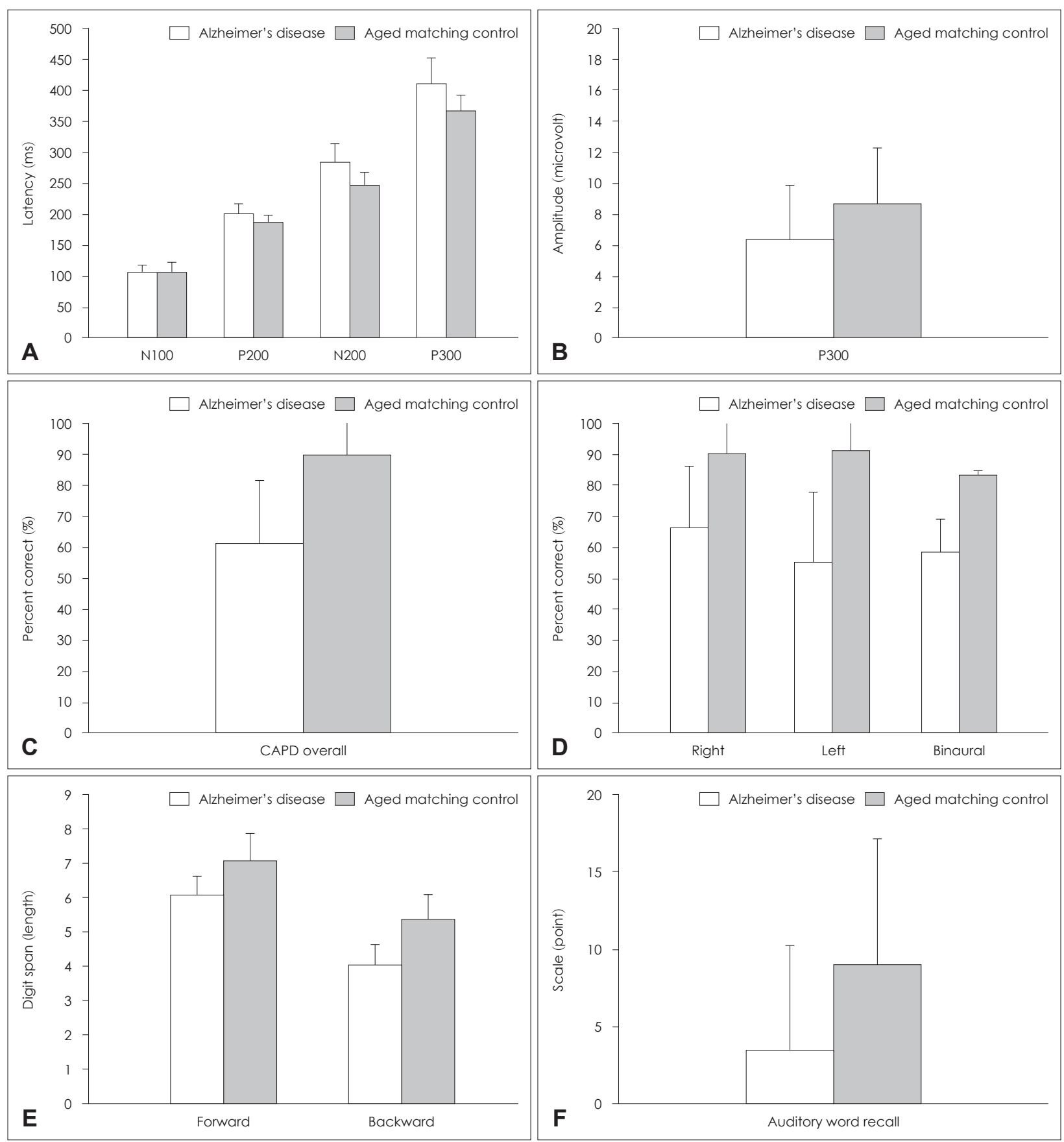

Fig. 2. Mean comparison between Alzheimer's disease and age matched groups plotted by 74 articles included in the meta-analysis. Latency auditory evoked potential (A), amplitude auditory evoked potential (B), central auditory processing tests (C), ear side of panel C $(D)$, digit span (E), auditory word recall $(E)$.

확인하였다[intercept=12.199, standard error(SE) $=3.047, p<$ 0.001]. 높은 이질성으로 인해 측정 전극에 대해 하위군 분석 을 실시하였으나, 자극음의 종류는 포함된 15 개의 데이터가 $1000 \mathrm{~Hz}$ 의 배경음, $2000 \mathrm{~Hz}$ 의 목표음으로 동일하여 하위군 분석을 실시하지 않았다.

전극 위치에 따른 하위군 분석 후에도, 여전히 높은 이질 성이 관찰되었다(SMD=1.973, 95\% CI=0.626 to $3.321, p=$
0.004; $\left.\mathrm{I}^{2}=93.37 \%\right)$. 하위군 분석에 포함된 15 개 데이터의 전극 위치(데이터수)는 $\mathrm{Cz}(8 / 15), \mathrm{Fz}(2 / 15), \mathrm{Oz}(1 / 15), \mathrm{Pz}(4 / 15)$ 였고, 주요 전극 위치의 효과 크기는 $\mathrm{Oz}(\mathrm{SMD}=4.366,95 \% \mathrm{CI}=1.799$ to $6.933, p<0.001), \mathrm{Fz}(\mathrm{SMD}=2.621,95 \% \mathrm{CI}=0.845$ to 4.397 , $p=0.004), \mathrm{Pz}(\mathrm{SMD}=1.366,95 \% \mathrm{CI}=0.136$ to $2.596, p=0.030$ ), $\mathrm{Cz}(\mathrm{SMD}=0.885,95 \% \mathrm{CI}=0.012$ to $1.759, p=0.047)$ 의 순으로 확인되어 $\mathrm{Oz}$ 위치에서 $\mathrm{AD}$ 환자군과 대조군의 $\mathrm{N} 100$ 의 잠복 
기 차이가 상대적으로 가장 컸다.

\section{P200 latency}

P200 잠복기에 관한 메타 분석은 10 개의 문헌에서 총 15 개 의 데이터를 추출하여 수행하였다. 포함된 15 개의 데이터 평 균은 Fig. 2A에 제시하였다(AD mean: 200.19 \pm 15.99 ms, control mean: $187.43 \pm 12.21 \mathrm{~ms})$. Egger's 회귀 비대칭 분석 결과에서 출판편향이 존재하지 않았지만(intercept $=-0.678$, $\mathrm{SE}=2.423, p=0.392)$, 종합적인 메타 분석의 결과는 유의한 차이를 확인할 수 없었고(SMD $=0.129,95 \% \mathrm{CI}=-0.131$ to $0.389, p=0.331)$, 중간크기의 이질성이 확인되어 $\left(\mathrm{I}^{2}=61.33 \%\right)$ 하 위군 분석을 측정 전극 및 자극음의 종류에 대해 실시하였다.

하위군 분석에 포함된 15 개의 전극 위치(데이터수)는 C5 (1/15), C6(1/15), Cz(8/15), Fz(1/15), Pz(4/15)였으며, 자극 음 의 종류는 $1000 / 2000(12 / 15)$ 와 250/4000(2/15)의 배경음/목 표음(데이터수), $800 \mathrm{~Hz}$ 단일 자극음(1/15)이었다. 전극 위치 에 따른 하위군 분석의 결과로 어느 정도 이질성이 해결되었 으나, 여전히 중간크기의 이질성이 확인되었다 $(\mathrm{SMD}=0.134$, $95 \% \mathrm{CI}=-0.173$ to $\left.0.440, p=0.394 ; \mathrm{I}^{2}=55.69 \%\right)$. 하위군 분석 으로 확인된 효과 크기는 $\mathrm{C} 5(\mathrm{SMD}=4.366,95 \% \mathrm{CI}=-0.529$ to $1.396, p=0.377), \mathrm{Pz}(\mathrm{SMD}=0.307,95 \% \mathrm{CI}=-0.160$ to 0.775 , $p=0.197), \mathrm{Fz}(\mathrm{SMD}=0.214,95 \% \mathrm{CI}=-0.775$ to $1.203, p=0.671$, $\mathrm{Cz}(\mathrm{SMD}=0.015,95 \% \mathrm{CI}=-0.336$ to $0.365, p=0.935), \mathrm{C} 6$ $(\mathrm{SMD}=-0.253,95 \% \mathrm{CI}=-1.212$ to $0.707, p<0.001)$ 의 측정 전극 순이였다. C5 위치에서 P200의 잠복기 차이가 비교적 컸으나 통계적으로 유의한 차이를 보여주지는 않았다. 또한, 해당 위치에서 측정된 데이터의 개수는 1 개로 다른 전극 위 치와의 직접적인 효과크기 비교가 어려웠다.

자극음에 따른 하위군 분석 또한 이질성이 어느 정도 해결 이 되었으나, 중간 크기의 이질성이 확인되었다 $(\mathrm{SMD}=0.069$, $95 \% \mathrm{CI}=-0.285$ to $\left.0.424, p=0.702 ; \mathrm{I}^{2}=55.69 \%\right) .1000 / 2000 \mathrm{~Hz}$ 집단에서 가장 큰 효과 크기를 보였으며 $(\mathrm{SMD}=0.185,95 \%$ $\mathrm{CI}=-0.081$ to $0.452, p=0.173)$, 그 다음으로 $250 / 4000 \mathrm{~Hz}$ 의 자극음 집단 $(\mathrm{SMD}=0.089,95 \% \mathrm{CI}=-0.549$ to $0.728, p=$ $0.784), 800 \mathrm{~Hz}$ 단일 자극음 집단 순으로 확인되었으나 모두 통계적으로 유의하지 않았다 $(\mathrm{SMD}=-0.415,95 \% \mathrm{CI}=-1.234$ to $0.403, p=0.320$ ).

\section{N200 latency}

$\mathrm{N} 200$ 잠복기의 메타 분석은 13 개의 문헌에서 총 16 개의 데 이터를 추출 후 실시하였다. 추출된 16 개의 데이터의 평균은 Fig. 2A에 제시되었다(AD mean: $283.05 \pm 31.66 \mathrm{~ms}$, control mean: $246.85 \pm 20.45 \mathrm{~ms})$. Egger's 회귀 비대칭 분석에서 출
판편향이 나타났다(intercept $=6.772, \mathrm{SE}=2.586, p=0.010$ ). 전 반적으로 $\mathrm{N} 200$ 잠복기에 유의한 차이를 보였으나 $\mathrm{SMD}=$ $1.144,95 \% \mathrm{CI}=0.475$ to $1.813, p<0.001)$, 높은 이질성으로 인해 전극 위치에 따른 반응의 잠복기를 하위군 분석으로 실 시하였다 $\left(\mathrm{I}^{2}=92.73 \%\right)$. 포함된 16 개의 데이터는 모두 배경음 $1000 \mathrm{~Hz}$, 목표음 $2000 \mathrm{~Hz}$ 을 사용하였다.

하위군 분석에 사용된 16 개의 데이터(데이터수)는 $\mathrm{Cz}(9 / 16)$, $\mathrm{Pz}(2 / 16), \mathrm{Fz}(5 / 16)$ 의 전극위치에서 측정되었으며, 하위군 분 석을 진행하였음에도 높은 이질성이 확인되었다 $\mathrm{SMD}=1.930$, $95 \% \mathrm{CI}=0.594$ to $\left.3.267, p=0.005 ; \mathrm{I}^{2}=90.97 \%\right)$. 각 하위군의 효과 크기는 $\mathrm{Fz}(\mathrm{SMD}=3.281,95 \% \mathrm{CI}=1.539$ to $5.023, p<$ 0.001), $\mathrm{Pz}(\mathrm{SMD}=2.084,95 \% \mathrm{CI}=1.027$ to $3.141, p<0.001)$, $\mathrm{Cz}(\mathrm{SMD}=0.911,95 \% \mathrm{CI}=0.131$ to $1.691, p=0.022)$ 의 순으로 나타나, $\mathrm{Fz}$ 위치에서 측정한 $\mathrm{N} 200$ 의 잠복기가 $\mathrm{AD}$ 환자군과 대조군 간의 차이를 명확하게 보여주는 것으로 확인되었다.

\section{P300 latency}

P300 잠복기의 메타 분석은 42개의 문헌이 포함되었으며, 총 69개의 데이터가 사용되었다. 포함된 69개의 데이터 평균 은 다른 측정 요소와 함께 Fig. 2A에 제시하였다(AD mean: $410.22 \pm 40.80 \mathrm{~ms}$, control mean: $366.46 \pm 25.98 \mathrm{~ms})$. P300 잠복기의 메타 분석 결과에서는 유의한 차이가 확인되었지 만(SMD=1.220, $95 \% \mathrm{CI}=0.936$ to $1.504, p<0.001)$, 이질성 또한 높게 확인되었다 $\left(\mathrm{I}^{2}=91.50 \%\right)$. 출판편향도 존재하였기에 (intercept $=6.089, \mathrm{SE}=1.067, p<0.001$ ), 자극음 종류와 전극 위치에 따른 하위군 분석을 진행하였다.

하위군 분석을 실시하여 어느 정도 이질성이 해결되었지만, 이질성은 여전히 높았다[전극위치: $(\mathrm{SMD}=1.315,95 \% \mathrm{CI}=$ 0.758 to $\left.1.872, p<0.001 ; \mathrm{I}^{2}=86.52 \%\right)$, 자극음: $(\mathrm{SMD}=0.960$, $95 \% \mathrm{CI}=0.261$ to $\left.\left.1.659, p=0.007 ; \mathrm{I}^{2}=86.52 \%\right)\right]$. 전극 위치에 따른 하위군 분석에 포함된 69개의 데이터 중에서 문헌에서 주로 사용된 전극(데이터수)인 $\mathrm{Cz}(26 / 69), \mathrm{Fz}(15 / 69), \mathrm{Pz}$ (25/69)의 결과를 바탕으로 비교하였다. 전극 위치에 따른 효 과 크기는 $\mathrm{Pz}(\mathrm{SMD}=1.332,95 \% \mathrm{CI}=0.974$ to $1.690, p<0.001)$, $\mathrm{Fz}(\mathrm{SMD}=1.096,95 \% \mathrm{CI}=0.745$ to $1.446, p<0.001), \mathrm{Cz}(\mathrm{SMD}=$ $1.332,95 \% \mathrm{CI}=0.974$ to $1.690, p<0.001)$ 순으로 나타나 $\mathrm{Pz}$ 의 전극 위치에서 $\mathrm{AD}$ 환자군과 대조군 간의 $\mathrm{P} 300$ 잠복기의 차 이가 가장 크게 확인되었다.

자극음에 따른 하위군 분석에 포함된 데이터의 자극음 종 류(데이터수)는 1000/2000 Hz(57/69), 1601/402 Hz(1/69), 250/4000 Hz(1/69), 500/1000 Hz(3/69), 750/2000 Hz(3/69), 980/1970 Hz(1/69), 숫자(1/69), 자극음 데이터 없음(2/69)으로 다양했다. 각 자극음 하위 그룹의 효과 크기는 다음과 같다: 
$1000 / 2000 \mathrm{~Hz}(\mathrm{SMD}=1.334,95 \% \mathrm{CI}=1.089$ to $1.580, p<$ 0.001), $1601 / 402 \mathrm{~Hz}(\mathrm{SMD}=0.450,95 \% \mathrm{CI}=-1.479$ to 2.380 , $p=0.647), 250 / 4000 \mathrm{~Hz}(\mathrm{SMD}=0.887,95 \% \mathrm{CI}=-0.916$ to 2.690 , $p=0.335), 500 / 1000 \mathrm{~Hz}(\mathrm{SMD}=0.410,95 \% \mathrm{CI}=-0.630$ to 1.451 , $p=0.439), 750 / 2000 \mathrm{~Hz}(\mathrm{SMD}=1.236,95 \% \mathrm{CI}=0.210$ to 2.263 , $p=0.018), 980 / 1970 \mathrm{~Hz}(\mathrm{SMD}=-1.189,95 \% \mathrm{CI}=-3.106$ to 0.728 , $p=0.224)$, 숫자(SMD=3.687, 95\% CI=1.276 to 6.097, $p=0.003)$, 자극음 데이터 없음 $(\mathrm{SMD}=1.108,95 \% \mathrm{CI}=-0.162$ to 2.378 , $p=0.087$ ).

\section{P300 amplitude}

P300 진폭의 메타 분석은 31 개의 문헌에서 총 56 개의 데 이터가 포함되었다. 56 개의 데이터의 평균은 Fig. $2 \mathrm{~B}$ 에 제시 하였다. 대조군 $(8.69 \pm 3.54 \mu \mathrm{V})$ 에 비해 $\mathrm{AD}$ 환자군의 P300 진 폭평균은 $6.39 \pm 3.48 \mu \mathrm{V}$ 로 작았다. 메타 분석 결과, $\mathrm{P} 300$ 진 폭의 유의한 차이가 확인되었으나 $(\mathrm{SMD}=-0.595,95 \% \mathrm{CI}=$ -0.907 to $-0.284, p<0.001)$ 높은 이질성이 확인되었고 $\left(\mathrm{I}^{2}=\right.$ 91.63\%), 출판편향 또한 존재하였다(intercept=-6.934, $\mathrm{SE}=$ $1.576, p<0.001) . \mathrm{P} 300$ 의 진폭 역시 높은 이질성으로 인해 전 극 위치와 자극음의 하위군 분석을 실시하였다.

하위군 분석 실시 후에도 여전히 높은 이질성이 관찰되었 다[전극위치: $(\mathrm{SMD}=-1.036,95 \% \mathrm{CI}=-1.594$ to $-0.477, p<$ $\left.0.001 ; \mathrm{I}^{2}=88.15 \%\right)$, 자극음: $(\mathrm{SMD}=-0.844,95 \% \mathrm{CI}=-1.526$ to $\left.\left.-0.162, p=0.015 ; \mathrm{I}^{2}=88.15 \%\right)\right]$. 전극 위치에 따른 하위군 분석 으로 $\mathrm{C} 3(\mathrm{SMD}=-2.922,95 \% \mathrm{CI}=-5.025$ to $-0.819, p=0.006)$, $\mathrm{C} 4(\mathrm{SMD}=-2.658,95 \% \mathrm{CI}=-4.733$ to $-0.584, p=0.012), \mathrm{FCz}$ $(\mathrm{SMD}=-0.468,95 \% \mathrm{CI}=-2.423$ to $1.486, p=0.639), \mathrm{Oz}(\mathrm{SMD}=$ $-2.733,95 \% \mathrm{CI}=-4.648$ to $-0.818, p=0.005)$ 는 각각 한 개의 데이터만이 추출되어 분석되었음으로 직접적인 비교가 어려 웠다. 따라서, 전극 위치(데이터수)는 $\mathrm{Cz}(19 / 56), \mathrm{Fz}(12 / 56)$, $\mathrm{Pz}(21 / 56)$ 의 결과가 비교되었다. 전극 위치에 따른 효과 크기 는 $\mathrm{Cz}(\mathrm{SMD}=-0.698,95 \% \mathrm{CI}=-1.135$ to $-0.261, p=0.002)$, $\mathrm{Pz}(\mathrm{SMD}=-0.696,95 \% \mathrm{CI}=-1.110$ to $-0.283, p<0.001)$, $\mathrm{Fz}(\mathrm{SMD}=-0.593,95 \% \mathrm{CI}=-1.139$ to $-0.047, p=0.033)$ 의 순 으로 확인되어, $\mathrm{Cz}$ 의 전극 위치에서 $\mathrm{AD}$ 환자군과 대조군 간 의 P300 진폭의 차이가 가장 크게 나타났다.

자극음 하위군 분석에 포함된 데이터(데이터수)는 1000/ $2000 \mathrm{~Hz}(43 / 56), 250 / 4000 \mathrm{~Hz}(1 / 56)$, 500/1000 Hz(2/56), 750/2000 Hz(3/56), 800/1200 Hz(3/56), 980/1970 Hz(1/56), 자극음 데이터 없음 $(3 / 56)$ 이었다. 하위군 분석의 효과 크기 결과는 $1000 / 2000 \mathrm{~Hz}(\mathrm{SMD}=-0.736,95 \% \mathrm{CI}=-1.036$ to $-0.436, p<0.001), 250 / 4000 \mathrm{~Hz}(\mathrm{SMD}=-0.240$, 95\% CI= -2.166 to $1.686, p=0.807), 500 / 1000 \mathrm{~Hz}(\mathrm{SMD}=-0.633,95 \%$
$\mathrm{CI}=-2.010$ to $0.745, p=0.368), 750 / 2000 \mathrm{~Hz}(\mathrm{SMD}=-0.217$, 95\% CI $=-1.315$ to $0.881, p=0.699), 800 / 1200 \mathrm{~Hz}(\mathrm{SMD}=$ $-2.722,95 \% \mathrm{CI}=-3.957$ to $-1.487, p<0.001), 980 / 1970 \mathrm{~Hz}$ $(\mathrm{SMD}=-0.468,95 \% \mathrm{CI}=-2.484$ to $1.548, p=0.649)$, 자극음 데이터 없음(SMD=-0.636, $95 \% \mathrm{CI}=-1.748$ to $0.476, p=0.262)$ 이었다.

\section{주관적 중추청각행동검사}

중추청각장애검사 배터리

중추청각장애검사는 8 개의 문헌이 포함되어 총 20 개의 데 이터가 메타 분석에 사용되었다. 20 개의 데이터 평균은 Fig. 2 C에 제시하였다(AD mean: $61.20 \pm 20.15 \%$, control mean: $90.03 \pm 10.41 \%$ ). 흥미롭게도, Fig. 2D에서는 $\mathrm{AD}$ 환자군의 우 측 귀 수행력이 $66.36 \pm 19.78 \%$ 였으며, 대조군은 $90.49 \pm 11.58 \%$ 의 수행력을 보였다. 좌측 귀 수행력의 평균은 $\mathrm{AD}$ 환자군이 $55.39 \pm 22.46 \%$ 였고, 대조군은 $91.15 \pm 10.32 \%$ 로, $\mathrm{AD}$ 환자군은 좌측 귀 수행력이 우측귀에 비해 약 $10 \%$ 낮았다. 양측 귀의 수행력 평균은 $\mathrm{AD}$ 환자군이 $58.70 \pm 10.60 \%$, 대조군이 83.30 $\pm 1.41 \%$ 로 확인되었다.

메타 분석 결과에서 유의한 차이가 확인되었으며(SMD= $-1.299,95 \% \mathrm{CI}=-1.512$ to $-1.086, p<0.001)$, 이질성도 낮았다 $\left(\mathrm{I}^{2}=13.49 \%\right)$. 출판편향은 존재하는 것으로 확인되었다(inter$\mathrm{cept}=-3.461, \mathrm{SE}=0.700, p<0.001)$. 메타 분석에 포함된 데이 터(데이터수)의 검사는 이분숫자청취(dichotic digits)(6/20), 이분문장청취(dichotic sentence)(2/20), 음장단패턴(duration pattern)(1/20), 주파수패턴(pitch pattern)(1/20), Synthetic Sentence Identification message-to-competition ratios (SSI/MCR) +10(2/20), SSI/MCR 0(2/20), SSI/MCR -10 (2/20), SSI/MCR -20(2/20), Synthetic Sentence Identification test with contralateral competing message(1/20), Synthetic Sentence Identification test with ipsilateral competing message(1/20)이 포함되었으며, 수행력을 측정한 귀 (데이터수)는 양측(2/20), 좌측(8/20), 우측(10/20)이었다.

\section{숫자 폭(Digit span) 검사}

숫자 바로 따라하기(digit span forward)의 메타 분석에 포 함된 문헌은 12 개였다. 포함된 12 개의 데이터 평균은 $\mathrm{AD}$ 환 자군이 6.09 \pm 0.52 였고, 대조군이 7.08 \pm 0.80 이었다(Fig. 2E). 숫자 바로 따라하기의 메타 분석 결과에서 유의한 차이가 확 인되었고 $(\mathrm{SMD}=-0.659,95 \% \mathrm{CI}=-0.918$ to $-0.399, p<0.001)$, 중간크기의 이질성이 확인되었다 $\left(\mathrm{I}^{2}=42.59 \%\right)$. 한편, 출판편향 은 존재하지 않는 것으로 확인되었다(intercept=-2.997, SE= 
2.715, $p=0.148)$. 하위군 분석은 검사 종류에 대해 실시되었으 며, 검사 종류(데이터수)는 웩슬러 지능 검사(Wechsler Adult Intelligence Scale-Revised, WAIS-R)(6/12)의 정량화된 결 과와 최대 숫자 수행력(6/12)이 하위군으로 포함되었다.

검사 종류에 따른 하위군 분석 결과는 포함된 문헌의 숫자 바로 따라하기 수행력에서 각각 한 개씩의 데이터만 보고되 어 이질성 결과는 동일하였다 $(\mathrm{SMD}=-0.660,95 \% \mathrm{CI}=-0.926$ to $\left.-0.394, p<0.001 ; \mathrm{I}^{2}=42.59 \%\right)$, 하위군의 개별적인 결과에 서 효과 크기의 차이는 상대적으로 WAIS-R이 높았으며 ( $\mathrm{SMD}=-0.747,95 \% \mathrm{CI}=-1.135$ to $-0.358, p<0.001$ ), 상당히 낮은 이질성을 보였다 $\left(\mathrm{I}^{2}=2.53 \%\right)$. 반면, 최대 숫자 수행력은 높은 이질성을 보였다 $(\mathrm{SMD}=-0.583,95 \% \mathrm{CI}=-0.949$ to $\left.-0.218, p=0.002 ; \mathrm{I}^{2}=61.96 \%\right)$.

숫자 거꾸로 따라하기(digit span backward)의 메타 분석에 포함된 문헌은 13 개이다. 포함된 13 개 데이터의 평균은 $\mathrm{AD}$ 환자군이 $4.06 \pm 0.59$, 대조군이 $5.37 \pm 0.72$ 였다(Fig. 2E). 출 판편향은 없는 것으로 확인되었으며(intercept $=-4.315, \mathrm{SE}=$ $2.510, p=0.057)$, 메타 분석 결과는 유의한 차이가 확인되었 고 중간크기의 이질성이 확인되었다 $(\mathrm{SMD}=-0.901,95 \% \mathrm{CI}=$ -1.179 to $-0.624, p<0.001 ; \mathrm{I}^{2}=51.71 \%$ ). 검사종류(데이터수) 에 따른 하위군 분석을 위해 WAIS-R(6/13), 최대 숫자 수행 력(7/13)이 하위군으로 포함되었다. 하위군 분석의 이질성은 숫자 바로 따라하기와 동일하였다(SMD=-0.904, 95\% CI= -1.190 to $\left.-0.617, p<0.001 ; \mathrm{I}^{2}=51.71 \%\right)$. 분석 결과, WAIS-R 의 효과 크기가 최대 숫자 수행력을 확인한 효과 크기보다 상대적으로 더 크게 나타났다[WAIS-R: (SMD $=-0.983,95 \%$ $\mathrm{CI}=-1.419$ to $-0.548, p<0.001 ; \mathrm{I}^{2}=42.01 \%$ ), 최대 숫자 수행 력: $\left(\mathrm{SMD}=-0.843,95 \% \mathrm{CI}=-1.223\right.$ to $-0.462, p<0.001 ; \mathrm{I}^{2}=$ 61.65\%)].

청각 단어 회상(Auditory word recall) 검사

청각 단어 회상 검사의 메타 분석은 15 개의 문헌에서 총 23 개의 데이터가 포함되었다. 추출된 23개의 데이터 평균은 $\mathrm{AD}$ 환자군이 $3.52 \pm 6.70$ 이었으며, 대조군은 $9.06 \pm 8.08$ 를 보 였다(Fig. $2 \mathrm{~F}$ ). 메타 분석 결과, 청각 단어 회상과제의 유의한 차이가 확인되었으나(SMD $=-2.308,95 \% \mathrm{CI}=-2.767$ to -1.848 , $p<0.001)$ 높은 이질성이 확인되었으며 $\left(\mathrm{I}^{2}=95.87 \%\right)$, 출판편향 또한 존재하였다(intercept=2.671, $\mathrm{SE}=1.538, p<0.048$ ). 높은 이질성으로 인해 회상에 대한 지연시간과 검사도구의 하위군 분석을 실시하였다.

하위군 분석을 실시하여 이질성이 일부 해결되었지만, 여전 히 이질성은 높게 나타났다[회상에 대한 지연시간: $(\mathrm{SMD}=$ $-2.267,95 \% \mathrm{CI}=-3.264$ to $-1.269, p<0.001 ; \mathrm{I}^{2}=91.96 \%$, 검
사도구: $(\mathrm{SMD}=-1.880,95 \% \mathrm{CI}=-2.911$ to $-0.850, p<0.001$; $\left.\left.\mathrm{I}^{2}=91.96 \%\right)\right]$. 회상에 대한 지연시간(데이터수)에 따른 하위군 분석으로 하위군은 구체적인 시간을 기재하지 않은 지연회 상(8/23), 즉시회상(3/23), 장기지연회상(6/23), 단기지연회상 (6/23)의 총 23개의 데이터가 포함된 4개의 군으로 나뉘었다. 개별 집단의 효과 크기는 장기지연회상 $(\mathrm{SMD}=-3.277,95 \%$ $\mathrm{CI}=-3.717$ to $-2.837, p<0.001)$, 단기지연회상 $(\mathrm{SMD}=-3.257$, $95 \% \mathrm{CI}=-3.697$ to $-2.818, p<0.001)$, 지연회상 $(\mathrm{SMD}=-2.296$, $95 \% \mathrm{CI}=-2.745$ to $-1.846, p<0.001)$, 즉시회상 $(\mathrm{SMD}=-0.222$, $95 \% \mathrm{CI}=-0.973$ to $0.529, p=0.563$ )순으로 확인되었다.

하위군 분석에 포함된 검사도구의 종류(데이터수)는 캘리포 니아 언어 학습 검사(California Verbal Learning Test, CVLT) (5/23), 레이 청각 언어 학습 검사(Rey Auditory Verbal Learning Test, RAVLT)(2/23), 청각 언어 학습검사(Auditory-Verbal Learning Test, AVLT)(11/23), 필라델피아 언어 학습 검 사(Philadelphia Verbal Learning Test, PVLT)(1/23), 웩슬러 지능 검사(2/23), Battery of Cognitive Assessment Instruments developed by World Health Organization(WHO$\mathrm{BCAI}$ (2/23)이었다. 각 검사에 대한 효과 크기는 청각 언어 학습검사(SMD $=-2.953,95 \% \mathrm{CI}=-3.216$ to $-2.691, p<0.001)$, 캘리포니아 언어 학습 검사(SMD=-3.451, 95\% CI=-3.927 to $-2.975, p<0.001)$, 필라델피아 언어 학습 검사 $(\mathrm{SMD}=3.381$, $95 \% \mathrm{CI}=2.068$ to $4.694, p<0.001)$, 레이 청각 언어 학습검사 ( $\mathrm{SMD}=-1.884,95 \% \mathrm{CI}=-2.645$ to $-1.123, p<0.001)$, 웩슬러 지능 검사 $(\mathrm{SMD}=-1.511,95 \% \mathrm{CI}=-2.281$ to $-0.741, p<0.001)$, WHO-BCAI(SMD $=-2.299,95 \% \mathrm{CI}=-2.951$ to $-1.646, p<$ 0.001)로 확인되었다.

\section{$\mathrm{DLB}$ 환자의 청각 기능을 위한 체계적 연구 결과 분석}

$\mathrm{DLB}$ 환자들을 대상으로 청각 검사를 실시한 문헌은 대상 자가 중복된 문헌을 포함하여 5 개로 확인되었다. 문헌의 수 의 부족과 검사 도구의 이질성으로 인해 메타 분석의 실시가 불가능하여 체계적 연구 결과 분석을 실시하였고 해당 문헌 에 대한 자세한 내용은 Table 3에 요약하여 정리하였다.

\section{객관적 청각유발전위 검사}

Bonanni 등 ${ }^{18)}$ 은 초기 $\mathrm{AD}$ 환자와 $\mathrm{DLB}$ 환자의 차이를 청 성후기반응(N100, P200, N200, P300)을 통해 확인하였다. 연구 대상자로는 $\mathrm{AD}$ 와 $\mathrm{DLB}$ 환자군과 정상 인지를 지닌 노 인 대조군이 포함되었다. 연구의 결과는 N100과 P200간의 잠복기, 진폭간의 차이는 확인할 수 없었고, N200과 P300간 의 잠복기는 세개의 집단간 유의미한 상관관계가 나타났다 $(\mathrm{r}=$ 0.6 0.7). 대조군의 결과를 기준으로 적용한 P300의 상대적 


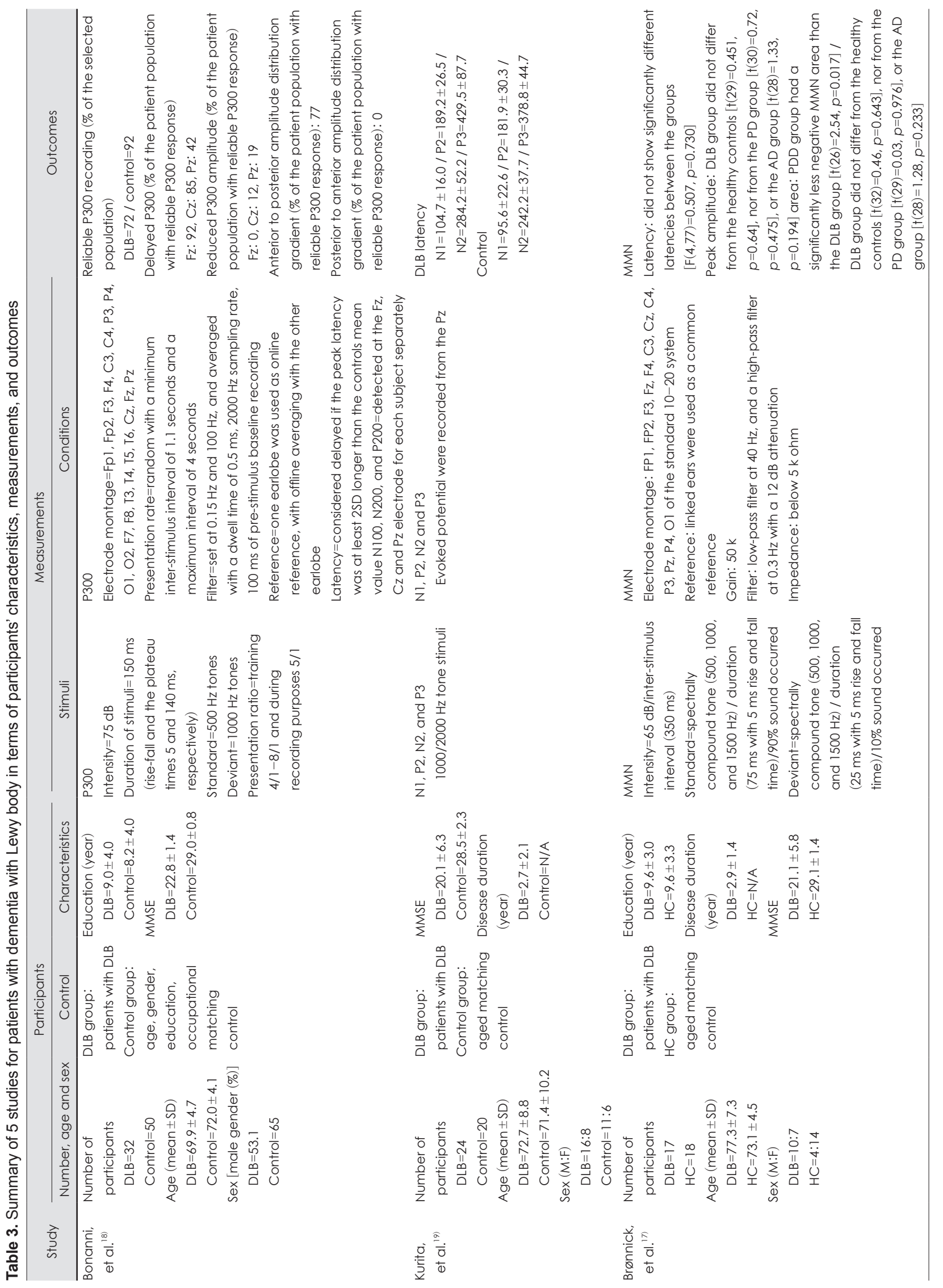




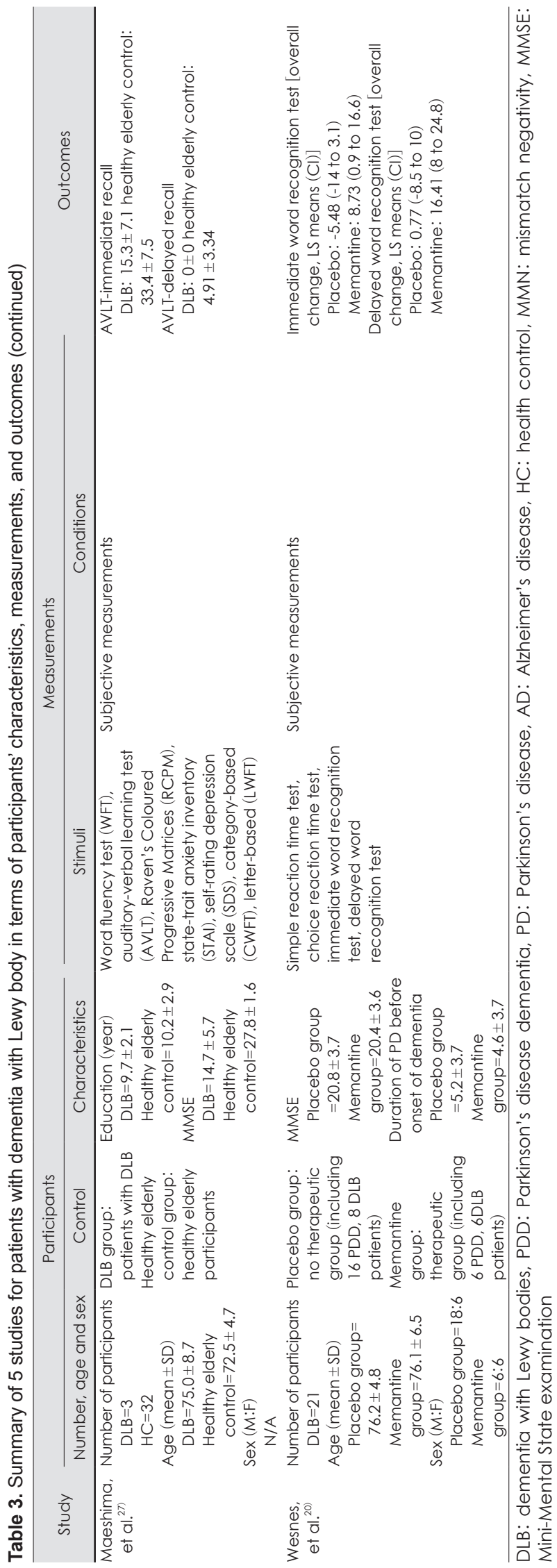

잠복기의 지연비율은 $\mathrm{Fz}$ 와 $\mathrm{CZ}$ 위치에서 $\mathrm{DLB}$ 환자 비율이 $\mathrm{AD}$ 환자 비율보다 높았으며, 통계적으로 유의한 결과를 보였 다[(Fz=AD: 55\%, DLB: 92\%, $p<0.01),(\mathrm{Cz}=\mathrm{AD}: 49 \%$, DLB: $85 \%, p<0.01)]$. 전두부에서 후두부로의 진폭 분포 변화 $(\mathrm{AD}=$ $3 \%, \mathrm{DLB}=77 \%, p<0.001)$ 와 후두부에서 전두부로의 진폭 분포 변화 $(\mathrm{AD}=36 \%, \mathrm{DLB}=0 \%, p<0.01)$ 도 통계적으로 유의 한 결과를 보였다. 대조군과 $\mathrm{AD}$ 환자군의 P300 반응의 진폭 은 $\mathrm{Pz}$ 에서 먼저 확인되는 반면, $\mathrm{DLB}$ 환자군은 $\mathrm{Fz}$ 위치에서 P300 반응의 진폭이 우선적으로 관찰되었다. DLB 환자의 P300 반응을 확인한 Kurita 등 ${ }^{19)}$ 의 연구에서도 정상 대조군 과의 비교에서 N200과 P300 반응의 잠복기에서 DLB 환자 의 잠복기 지연으로 인한 유의한 차이가 확인되었다 $[(\mathrm{N} 2$ 잠 복기=정상 대조군: $242.2 \pm 37.7$, DLB: 284.2 $\pm 52.2, p<0.01$, (P3 잠복기=정상 대조군: $378.8 \pm 44.7, \mathrm{DLB}: 429.5 \pm 87.7, p<$ 0.05)]. 결과를 종합해 보면, P300 잠복기는 AD과 DLB 환자 에서 모두 지연되는 결과를 보여주어 절대 잠복기는 정상 대 조군과 $\mathrm{AD}, \mathrm{DLB}$ 환자를 구분하는 지표가 될 수 있으며, 반 응의 위치에 따른 잠복기 변화로 $\mathrm{AD}$ 환자와 DLB 환자를 구 분할 수 있다.

$\mathrm{Br} \varnothing n$ nick 등 ${ }^{17)}$ 은 여러 유형의 치매 환자군에게 $\mathrm{MMN}$ 을 적용하여 청각 자극의 선택적 주의력을 확인하였다. 연구 대 상자들은 $\mathrm{DLB}, \mathrm{PDD}, \mathrm{PD}, \mathrm{AD}$, 정상 대조군의 총 5그룹으로 구성되었다. 결과를 요약하면 $\mathrm{MMN}$ 반응의 진폭은 $\mathrm{PD}$ 환 자군에서 가장 크게 관찰되었으며(-3.67 \pm 1.24$)$, 뒤이어 DLB (-3.34 \pm 1.42$)$, 정상 대조군 $(-3.14 \pm 1.05), \mathrm{AD}(-2.59 \pm 1.78)$, $\mathrm{PDD}(-2.31 \pm 0.92)$ 순으로 관찰되어, $\mathrm{DLB}$ 환자군과 $\mathrm{PDD}$ 환 자군 간 $\mathrm{MMN}$ 반응 진폭에서 유의한 차이가 관찰되었다 $(p=$ $0.02) . \mathrm{MMN}$ 반응 면적 또한 DLB 환자군(-82.43 \pm 50.34$)$ 과 $\mathrm{PDD}$ 환자군(-29.15 \pm 66.04$)$ 간 유의한 차이가 확인되어 $(p=$ $0.017)$, 진폭과 면적에서 $\mathrm{PDD}$ 환자군이 가장 작은 반응을 나타냈다.

\section{주관적 중추청각행동검사}

Maeshima 등 ${ }^{27}$ 은 청각 언어 학습 검사를 사용하여 $\mathrm{AD}$, $\mathrm{DLB}$, 혈관성치매(vascular dementia, VD), 전두측두엽치매 (frontotemporal dementia, FTD), 노인 대조군 대상자의 청 각 단어 회상 능력을 평가하였다. 결과적으로 즉시회상과 지 연회상 검사에서 청각 단어 회상 능력은 대조군과 모든 치매 환자군간 유의한 차이가 확인되었다[(즉시회상=AD: $13.9 \pm$

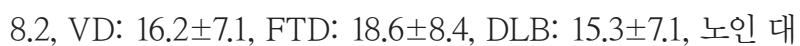
조군: $33.4 \pm 7.5, p<0.0001$ ), (지연회상=AD: $0.28 \pm 0.92, \mathrm{VD}$ : $0.69 \pm 1.56$, FTD: $0.50 \pm 1.15$, DLB: $0 \pm 0$, 노인 대조군: 4.91 $\pm 3.34, p<0.0001)]$. $\mathrm{DLB}$ 와 $\mathrm{PDD}$ 환자를 대상으로 단어인지 
검사를 통해 청각 언어 인지 능력을 확인한 Wesnes 등이 의 선행 연구에서는 Memantine 약의 효과를 확인하기 위하여 위약군과 실험군으로 $\mathrm{PDD}$ 환자와 $\mathrm{DLB}$ 환자를 무작위로 할 당하여 배치하였다. 그러나, 아쉽게도 해당 문헌에서는 PDD 와 DLB 환자의 실제적인 각각의 데이터는 확인할 수 없었다.

\section{$\mathrm{PDD}$ 환자의 청각 기능을 위한 체계적 연구결과 분석}

대상자가 중복된 문헌을 포함하여 $\mathrm{PDD}$ 환자군은 6 개의 문헌이 확인되었다. 문헌의 수의 부족과 검사 도구의 이질성 으로 인해 DLB 환자군에서와 마찬가지로 메타 분석이 불가 능하였다. 따라서 체계적 연구결과분석을 실시 후 Table 4에 결과를 요약하였다.

\section{객관적 청각유발전위 검사}

Kurita 등 ${ }^{19)}$ 은 $\mathrm{AD}, \mathrm{DLB}$, 환시의 증상을 보이는 $\mathrm{PDD}$, 환 시의 증상이 없는 $\mathrm{PDD}$ 환자군을 대상으로 청성후기반응 (N100, P200, N200, P300)을 측정하였다. 환시가 없는 PDD 대상자와 정상 대조군과의 $\mathrm{P} 300$ 의 잠복기에서 유의한 차이 가 관찰되었으며(정상 대조군: $378.8 \pm 44.7$, 환시가 없는 $\mathrm{PDD}$ : $445.3 \pm 66.1, p<0.01)$, 환시가 있는 PDD 대상자와 정상 대조 군의 N200 잠복기(정상 대조군: $242.2 \pm 37.7$, 환시가 있는 $\mathrm{PDD}: 283.2 \pm 52.3, p<0.05$ )와 $\mathrm{P} 300$ 잠복기(정상 대조군: $378.8 \pm 44.7$, 환시가 있는 $\mathrm{PDD}: 436.4 \pm 89.3, p<0.05)$ 에도 유 의한 차이가 관찰되었다. 앞서 확인한 $\mathrm{Br} ø$ nnick 등 ${ }^{17}$ 의 연구 에서도 $\mathrm{MMN}$ 반응은 $\mathrm{DLB}$ 환자군과 $\mathrm{PDD}$ 환자군 간에 진 폭 $(p=0.02)$ 과 면적 $(p=0.017)$ 에서 유의한 차이가 관찰되었다. Yamamoto 등 ${ }^{28}$ 의 연구에서는 PDD 환자의 P300 반응 잠복 기와 MMSE 점수의 상관분석을 실시하였고, $\mathrm{PDD}$ 대상자의 P300 잠복기 결과는 MMSE 점수가 17 이상인 경증 치매 환 자에서 $\mathrm{MMSE}$ 점수와 강한 음의 상관 관계를 보여주었다 $(\mathrm{r}=$ $-0.808 ; p<0.001)$.

\section{주관적 중추청각행동검사}

주관적 측정방법을 활용하여 $\mathrm{PDD}$ 환자군의 청각 능력을 확인한 Claus와 $\mathrm{Mohr}^{29)}$ 은 이분청취검사를 실시하였다. 연구 대상자는 $\mathrm{AD}$, 헌팅턴병, $\mathrm{PDD}, \mathrm{PD}$, 대조군이 포함되었다. 자 유회상 검사의 좌측 귀 수행력에서 $\mathrm{PDD}$ 환자군 $0.28 \pm 0.15$ 의 수행력을 보여 정상 대조군 $(0.39 \pm 0.12, p<0.05)$ 과 파킨슨 병 대상자 $(0.41 \pm 0.13, p<0.05)$ 와 유의한 차이를 보였으며, 좌 측 귀 회상(left ear recall)검사의 좌측 귀 수행력에서 $0.40 \pm$ 0.17 의 수행력을 보여 정상 대조군 $(0.60 \pm 0.12, p<0.01)$ 과 $\mathrm{PD}$ $(0.57 \pm 0.16, p<0.05)$ 와 유의한 차이를 보였다. 또한, 우측 귀 회상(right ear recall) 검사에서 우측 귀 수행력은 $0.44 \pm 0.23$
으로 확인되어 정상 대조군과 유의한 차이를 보였으며( $0.64 \pm$ $0.11, p<0.01$, 좌측 귀 수행력은 $0.28 \pm 0.15$ 로 $\mathrm{PD}$ 와 유의한 차이를 보였다 $(0.41 \pm 0.12, p<0.05)$. Wesnes 등 $^{20}$ 의 연구에서 는 단어 인지 검사를 실시하였지만, $\mathrm{PDD}$ 환자만의 순수한 결 과는 확인할 수 없었으며, Schmitt 등 ${ }^{30}$ 의 연구에서도 PDD 환자군의 청각 언어인지 검사를 실시하였지만, rivastigmine 약물 복용 및 플라시보 효과에 대한 수행력 변화만을 보고 하였다.

\section{결 론}

본 종설은 치매 유형에 따른 치매 환자들의 청각 기능을 구분하고자 72 건의 $\mathrm{AD}$ 환자들의 객관적 청성유발전위 및 주관적 중추청각행동검사의 선행 연구 결과를 바탕으로 메타 분석을 실시하였고, $\mathrm{DLB}$ 환자군과 $\mathrm{PDD}$ 환자군을 대상으로 의미 있는 결과를 보고한 각 5 편 및 6 편의 논문들의 연구 결 과를 체계적으로 분석하였다.

먼저, 청성유발전위 반응의 결과를 기반으로 시행한 메타 분석 결과는 $\mathrm{AD}$ 환자군과 정상 인지를 갖은 노인 대조군과 의 비교에서 $\mathrm{N} 200$ 과 $\mathrm{P} 300$ 잠복기의 유의한 지연이 관찰되 었지만[(N200: $\mathrm{SMD}=1.144,95 \% \mathrm{CI}=0.475$ to $1.813, p<0.001$ ), (P300: $\mathrm{SMD}=1.220,95 \% \mathrm{CI}=0.936$ to $1.504, p<0.001$ )], $\mathrm{N} 100$ 과 $\mathrm{P} 200$ 의 잠복기에서는 유의한 차이가 확인되지 않았 다[(N100: $\mathrm{SMD}=0.672,95 \% \mathrm{CI}=-0.051$ to $1.395, p=0.069)$, (P200: $\mathrm{SMD}=0.129,95 \% \mathrm{CI}=-0.131$ to $0.389, p=0.331)]$. 이 러한 분석은 $\mathrm{AD}$ 환자군이 $\mathrm{N} 200$ 의 잠복기부터 순차적으로 유의하게 지연되는 결과를 보여 선행 메타 분석 연구의 결과 와 일치성을 나타냈다.,4) 또한 P300의 진폭 역시 유의하게 감 소된 결과를 나타내 Hedges 등 ${ }^{5}$ 의 메타 분석 결과와 일치하 였다. 그러나 선행연구에서도 확인된 높은 이질성은 본 연구 에서도 유사하게 확인되었다. Howe 등)은 P300 잠복기에 영 향을 주는 요인으로 환자군의 평균 연령, 자극 간 간격 및 자 극 주파수, 기준 전극, 샘플링 주기를 지적하였고, Hedges 등5) 은 메타 회귀분석을 실시하여 P300 진폭의 결과의 이질성의 원인이 환자군의 교육 수준에 있다고 결론내렸다. 따라서 검 사방법, MMSE 점수, 자극의 타입(click/tone), 자극기간, 자 극강도, 자극빈도, 평균연령, 교육수준, 기준전극, 자극 주파 수, 샘플링주기, 필터 등 다양한 원인들에 의해 청성유발전위 의 메타 분석 결과에서 높은 이질성을 보인 것으로 사료되기 에 향후 청성유발전위의 검사 셋팅 및 임상적 기준을 보다 명 확히 설정하여 일관된 반응을 이끄는 연구들이 필요하다.

주관적 중추청각행동검사에서는 중추청각처리능력, 숫자 바로 따라하기, 숫자 거꾸로 따라하기, 청각 단어 회상 능력에 


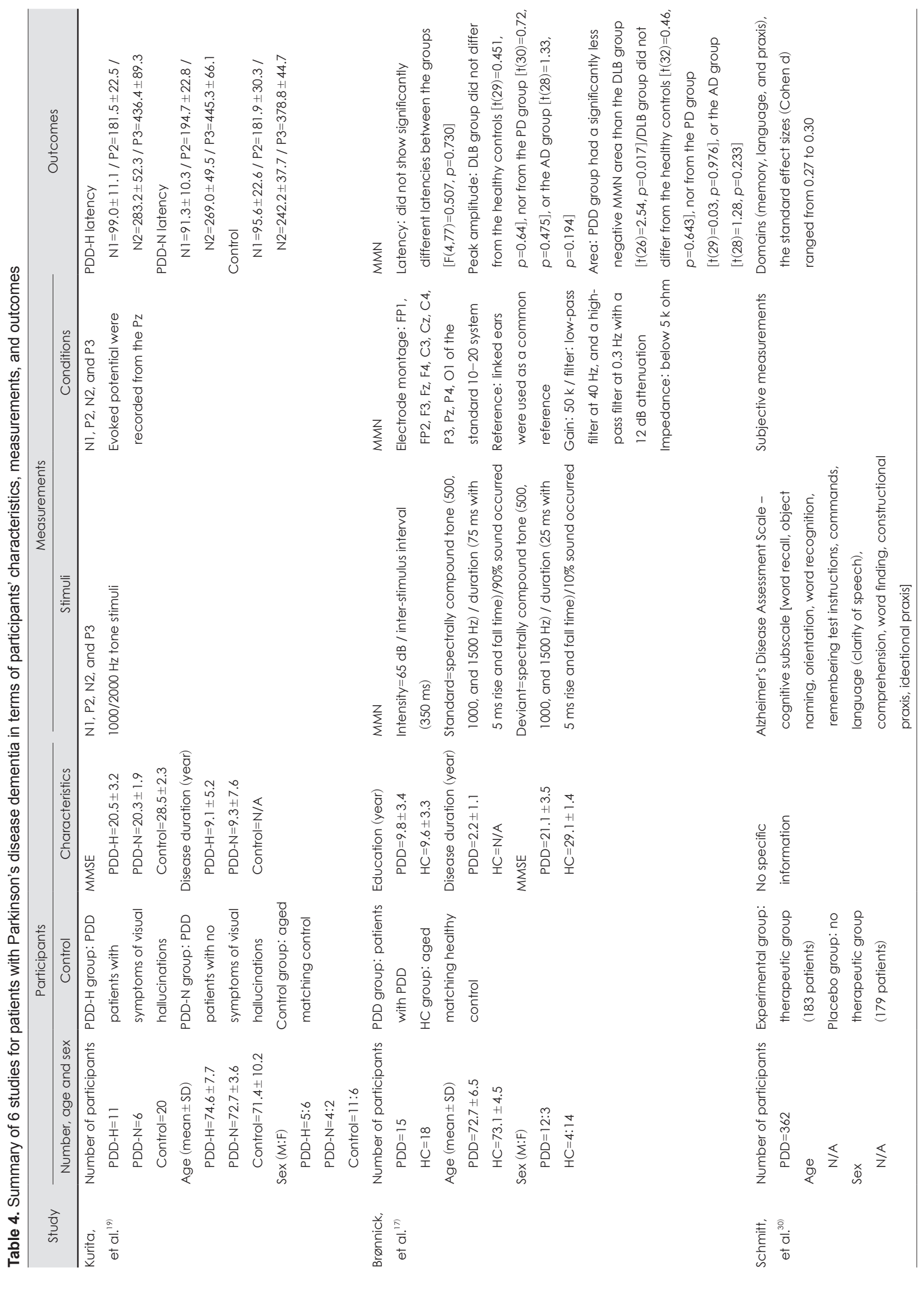




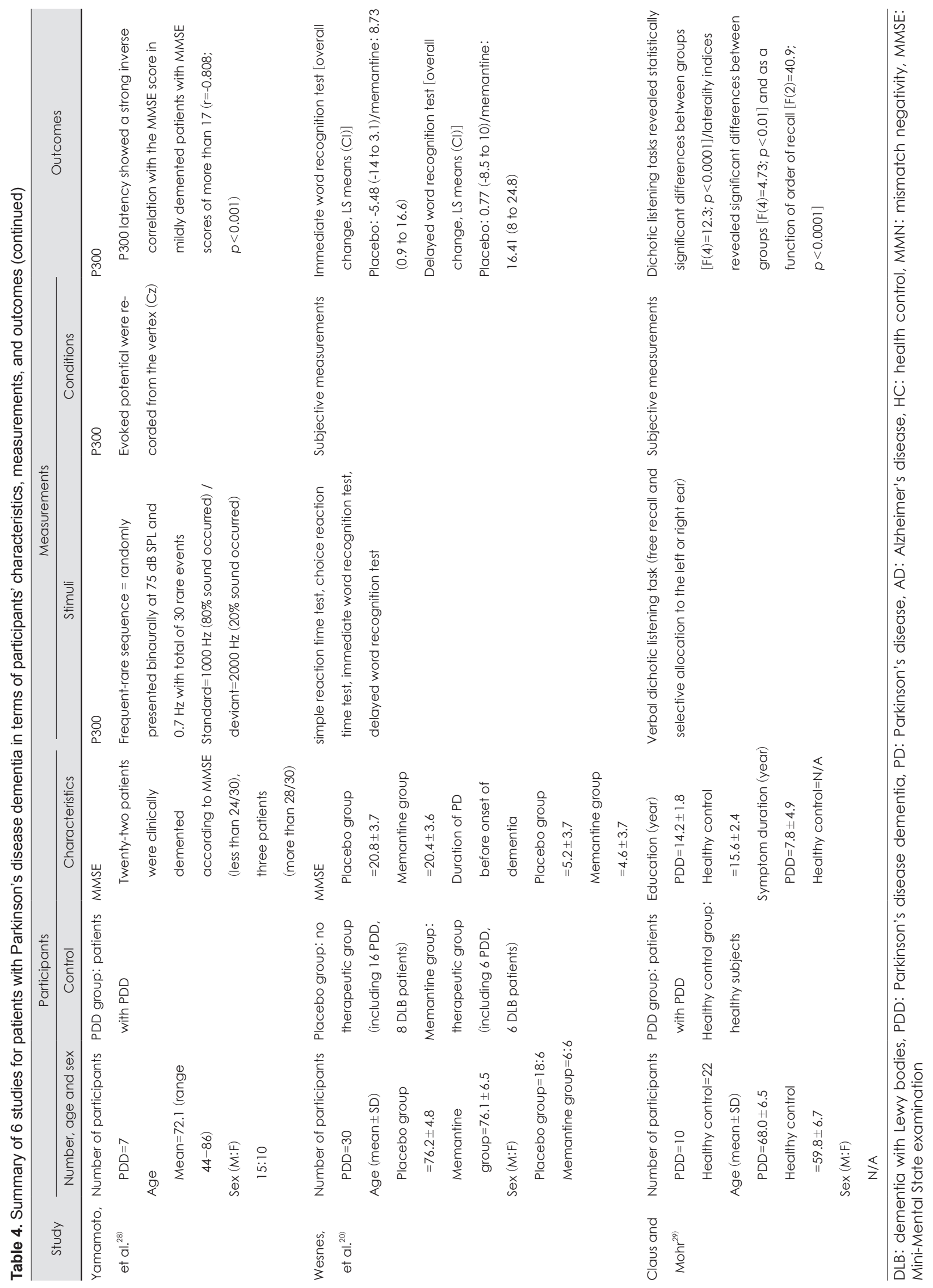


Auditory Functions for Dementia I Park S, et al.

Table 5. The audiological tests having significant differences when comparing the normal control group with health cognition

\begin{tabular}{|c|c|c|c|c|c|c|c|c|c|c|}
\hline & \multicolumn{6}{|c|}{ Auditory event-related potentials } & \multicolumn{4}{|c|}{ Central auditory processing tests } \\
\hline & NIOOL & P200L & N2OOL & P300L & P300A & MMN & CAPD test & $\begin{array}{c}\text { Digit } \\
\text { forward }\end{array}$ & $\begin{array}{c}\text { Digit } \\
\text { backward }\end{array}$ & $\begin{array}{l}\text { Auditory } \\
\text { word recall }\end{array}$ \\
\hline$A D$ & $x$ & $x$ & 0 & 0 & 0 & N/A & 0 & 0 & 0 & 0 \\
\hline DLB & $x$ & $x$ & 0 & 0 & 0 & Sig. b/t two & N/A & N/A & N/A & 0 \\
\hline PDD & $x$ & $x$ & $x$ & 0 & N/A & groups & 0 & N/A & N/A & N/A \\
\hline
\end{tabular}

L: latency, A: amplitude, N/A: not applicable, MMN: mismatch negativity, CAPD: Central auditory processing disorder, AD: Alzheimer's disease, DLB: dementia with Lewy bodies, PDD: Parkinson's disease dementia, 0: significance, $x$ : no significance, N/A: not applicable due to no test results

서 유의한 차이가 확인되었다. 또한 중추청각처리검사의 결 과가 낮은 이질성과 유의한 수행력의 차이를 보여 임상적 활 용 가능성이 높게 판단되었다. 병리학적 위치와 청각적 기능 의 연관성을 확인할 때, 대부분은 중추청각처리 과정과 관련 이 있음에도 불구하고 중추청각처리능력을 진단할 수 있는 국내의 표준화된 검사가 현재 부재하고 국외에서도 중추청각 처리검사 결과에서 피험자간/피험자내 변이(inter/intra subject variance)가 높기에 실제 임상적 활용은 크지 않다. 그러 나 메타 분석에서 의미 있는 결과가 확인된 만큼 향후 치매 환자들을 위한 중추청각처리검사의 적용이 여러 연구에서 시도되어야 하겠다.

한편, $\mathrm{DLB}$ 환자와 $\mathrm{PDD}$ 환자에게 청각 검사를 적용한 연 구들을 체계적으로 결과 분석 시, P300의 잠복기는 DLB와 $\mathrm{PDD}$ 환자군 모두 유의하게 지연된 결과를 확인하였고, $\mathrm{P} 300$ 의 진폭 분포 변화는 $\mathrm{DLB}$ 환자와 $\mathrm{AD}$ 환자, 대조군에서 유 의한 차이를 보였다. 또한, $\mathrm{PDD}$ 환자군과 $\mathrm{DLB}$ 환자군 간에 $\mathrm{MMN}$ 진폭 및 면적에서 유의한 차이를 보였다. DLB 환자군 은 대조군과의 비교에서 청각 단어 회상 능력의 유의한 차이 를 보였으며, $\mathrm{PDD}$ 환자군은 이분청취검사에서 우측 귀 수행 력이 대조군보다 낮게 나타나 유의한 차이를 보였다.

Table 5는 본 종설 논문에서 다룬 결과들을 종합하여 $\mathrm{AD}$, $\mathrm{DLB}, \mathrm{PDD}$ 환자군에서 청각 기능의 저하로 확인된 검사들을 표기하였다. $\mathrm{DLB}$ 와 $\mathrm{PDD}$ 환자들의 청각적 연구가 매우 적어 본 결과를 일반화하기에는 아직 시기적으로 이르지만, P300 잠복기는 치매의 유형에 상관없이 대조군과 비교 시 모두 유 의하게 지연되었다. 따라서 치매의 유무를 확인하기 위한 검사 로는 P300 잠복기의 비교를 제안한다. 몇몇 연구에서는 지연 된 P300 잠복기의 정도를 통해 치매 유형을 구분하였지만, ${ }^{18)}$ 일부 문헌에서는 지연된 P300 잠복기의 정도가 치매 유형간 유의한 차이를 보이지 않았다..$^{19)}$ 만약 치매의 유형에 따른 청 각 기능의 차이를 구분하고자 한다면, MMN 결과와 P300 진폭 분포 변화를 활용하는 것을 제안한다. 특히 $\mathrm{MMN}$ 검 사에서는 정상 인지의 대조군과는 통계적 차이가 없었지만, $\mathrm{DLB}$ 환자군과 PDD 환자군 간의 비교에서는 유의한 차이를
보여주어 $\mathrm{MMN}$ 의 진폭 및 면적을 비교하여 치매의 유형 간 차별성을 이끌 수 있을 것으로 사료된다. ${ }^{17}$

본 종설의 한계점으로는 아쉽게도 메타 분석 결과에서 높 은 이질성이 확인되어 직접적인 임상적 적용은 단언하기 보 다는 청성유발전위 검사의 셋팅과 기준에서 클리닉 간 통일성 이 필요할 것으로 판단된다. 또한 $\mathrm{AD}$ 환자들에 비하여 $\mathrm{DLB}$ 및 $\mathrm{PDD}$ 환자들을 대상으로 청각적 수행력을 확인한 문헌은 매우 제한적이었다. 따라서 유형별 치매 환자군에게 청각 검 사를 적용하고 더 많은 기초 데이터가 축적되어 치매 유형 간 차별화된 청각 선별 도구가 확보될 필요가 있다.

\section{Acknowledgments}

This work was supported by the National Research Foundation of Korea(NRF) grant funded by the Korea government (MSIT) (2019R1F1A1053060).

\section{Author Contribution}

Conceptualization: Sihun Park, Woojae Han, Tae Hui Kim. Formal analysis: Tae Hui Kim. Investigation: Sihun Park. Methodology: Tae Hoon Kong, Jaehyun Han. Project administration: Woojae Han, Young Joon Seo. Supervision: Tae Hui Kim. Writing-original draft: Sihun Park, Woojae Han. Writing — review \& editing: all authors

\section{ORCIDs}

Woojae Han

Sihun Park

Tae Hoon Kong

Young Joon Seo

Jaehyun Han

Tae Hui Kim

https://orcid.org/0000-0003-1623-9676 https://orcid.org/0000-0001-6085-2107 https://orcid.org/0000-0002-5612-5705 https://orcid.org/0000-0003-1169-0441 https://orcid.org/0000-0002-7941-1763 https://orcid.org/0000-0003-0133-5227

\section{REFERENCES}

1) Nadhimi Y, Llano DA. Does hearing loss lead to dementia? A review of the literature. PsyArXiv [preprint], 27 May 2020. Available from: https://doi.org/10.31234/osf.io/zgkvr.

2) Häggström J, Hedrstierna C, Rosenhall U, Östberg P, Idrizbegovic E. Prognostic value of a test of central auditory function in conversion from mild cognitive impairment to dementia. Audiol Neurootol 2020;25(5):276-82

3) Howe AS. Meta-analysis of the endogenous N200 latency eventrelated potential subcomponent in patients with Alzheimer's disease and mild cognitive impairment. Clin Neurophysiol 2014;125(6): 
1145-51.

4) Howe AS, Bani-Fatemi A, De Luca V. The clinical utility of the auditory P300 latency subcomponent event-related potential in preclinical diagnosis of patients with mild cognitive impairment and Alzheimer's disease. Brain Cogn 2014;86:64-74.

5) Hedges D, Janis R, Mickelson S, Keith C, Bennett D, Brown BL. P300 amplitude in Alzheimer's disease: A meta-analysis and metaregression. Clin EEG Neurosci 2016;47(1):48-55.

6) Kim DS., Kim YB. A topographically correlational study of P300 and MMN (mismatch negativity) in healthy subjects. Korean J Clin Lab Sci 2007;39(3):256-63.

7) Hillyard SA, Hink RF, Schwent VL, Picton TW. Electrical signs of selective attention in the human brain. Science 1973;182(4108):17780.

8) Moussaud S, Jones DR, Moussaud-Lamodière EL, Delenclos M, Ross OA, McLean PJ. Alpha-synuclein and tau: Teammates in neurodegeneration? Mol Neurodegener 2014;9:43.

9) Duda JE, Giasson BI, Mabon ME, Lee VMY, Trojanowski JQ. Novel antibodies to synuclein show abundant striatal pathology in Lewy body diseases. Ann Neurol 2002;52(2):205-10.

10) Taylor A, Yardley C. Advocacy, education, and the role of not-forprofit organizations in Lewy body dementias. Alzheimers Res Ther 2014;6(5):59.

11) Hardy CJ, Marshall CR, Golden HL, Clark CN, Mummery CJ, Griffiths TD, et al. Hearing and dementia. J Neurol 2016;263(11): 2339-54.

12) Goll JC, Kim LG, Hailstone JC, Lehmann M, Buckley A, Crutch $\mathrm{SJ}$, et al. Auditory object cognition in dementia. Neuropsychologia 2011;49(9):2755-65.

13) Goll JC, Kim LG, Ridgway GR, Hailstone JC, Lehmann M, Buckley $\mathrm{AH}$, et al. Impairments of auditory scene analysis in Alzheimer's disease. Brain 2012;135(Pt 1):190-200.

14) Cheng CH, Wang PN, Hsu WY, Lin YY. Inadequate inhibition of redundant auditory inputs in Alzheimer's disease: An MEG study. Biol Psychol 2012;89(2):365-73.

15) Grahn JA, Brett M. Impairment of beat-based rhythm discrimination in Parkinson's disease. Cortex 2009 Jan;45(1):54-61.

16) Gates GA, Mills JH. Presbycusis. Lancet 2005;366(9491):1111-20.

17) Brønnick KS, Nordby H, Larsen JP, Aarsland D. Disturbance of automatic auditory change detection in dementia associated with Parkinson's disease: A mismatch negativity study. Neurobiol Aging 2010;31(1):104-13.

18) Bonanni L, Franciotti R, Onofrj V, Anzellotti F, Mancino E, Monaco
D, et al. Revisiting P300 cognitive studies for dementia diagnosis: Early dementia with Lewy bodies (DLB) and Alzheimer disease (AD). Neurophysiol Clin 2010;40(5-6):255-65.

19) Kurita A, Murakami M, Takagi S, Matsushima M, Suzuki M. Visual hallucinations and altered visual information processing in Parkinson disease and dementia with Lewy bodies. Mov Disord 2010;25(2):167-71.

20) Wesnes KA, Aarsland D, Ballard C, Londos E. Memantine improves attention and episodic memory in Parkinson's disease dementia and dementia with Lewy bodies. Int J Geriatr Psychiatry 2015; 30(1):46-54.

21) Huang X, Lin J, Demner-Fushman D. Evaluation of PICO as a knowledge representation for clinical questions. AMIA Annu Symp Proc 2006;2006:359-63.

22) Moher D, Shamseer L, Clarke M, Ghersi D, Liberati A, Petticrew $\mathrm{M}$, et al. Preferred reporting items for systematic review and metaanalysis protocols (PRISMA-P) 2015 statement. Syst Rev 2015; 4(1):1.

23) McKeith IG, Galasko D, Kosaka K, Perry EK, Dickson DW, Hansen LA, et al. Consensus guidelines for the clinical and pathologic diagnosis of dementia with Lewy bodies (DLB): Report of the consortium on DLB international workshop. Neurology 1996;47(5): 1113-24.

24) Higgins JPT, Altman DG. Assessing risk of bias in included studies. In: Higgins JPT, Green S, editors. Cochrane Handbook for Systematic Reviews of Interventions. Chichester: John Wiley \& Sons;2008. p.187-241.

25) Borenstein M, Hedges LV, Higgins JP, Rothstein HR. Introduction to meta-analysis. Chichester: John Wiley \& Sons;2009.

26) Egger M, Davey Smith G, Schneider M, Minder C. Bias in metaanalysis detected by a simple, graphical test. BMJ 1997;315(7109): 629-34.

27) Maeshima S, Osawa A, Maeshima E, Shimamoto Y, Sekiguchi E, Kakishita K, et al. Usefulness of a cube-copying test in outpatients with dementia. Brain Inj 2004;18(9):889-98.

28) Yamamoto M, Kachi T, Igata A. Pain-related somatosensory evoked potentials in dementia. J Neurol Sci 1996;137(2):117-9.

29) Claus JJ, Mohr E. Attentional deficits in Alzheimer's, Parkinson's, and Huntington's diseases. Acta Neurol Scand 1996;93(5):346-51.

30) Schmitt FA, Aarsland D, Brønnick KS, Meng X, Tekin S, Olin JT. Evaluating rivastigmine in mild-to-moderate Parkinson's disease dementia using ADAS-cog items. Am J Alzheimers Dis Other Demen 2010;25(5):407-13. 


\section{Appendix 1}

The meta-analysis results for components of event-related potentials A: N100 latency, B: P200 latency, C: N200 latency, D: P300 latency, E: P300 amplitude

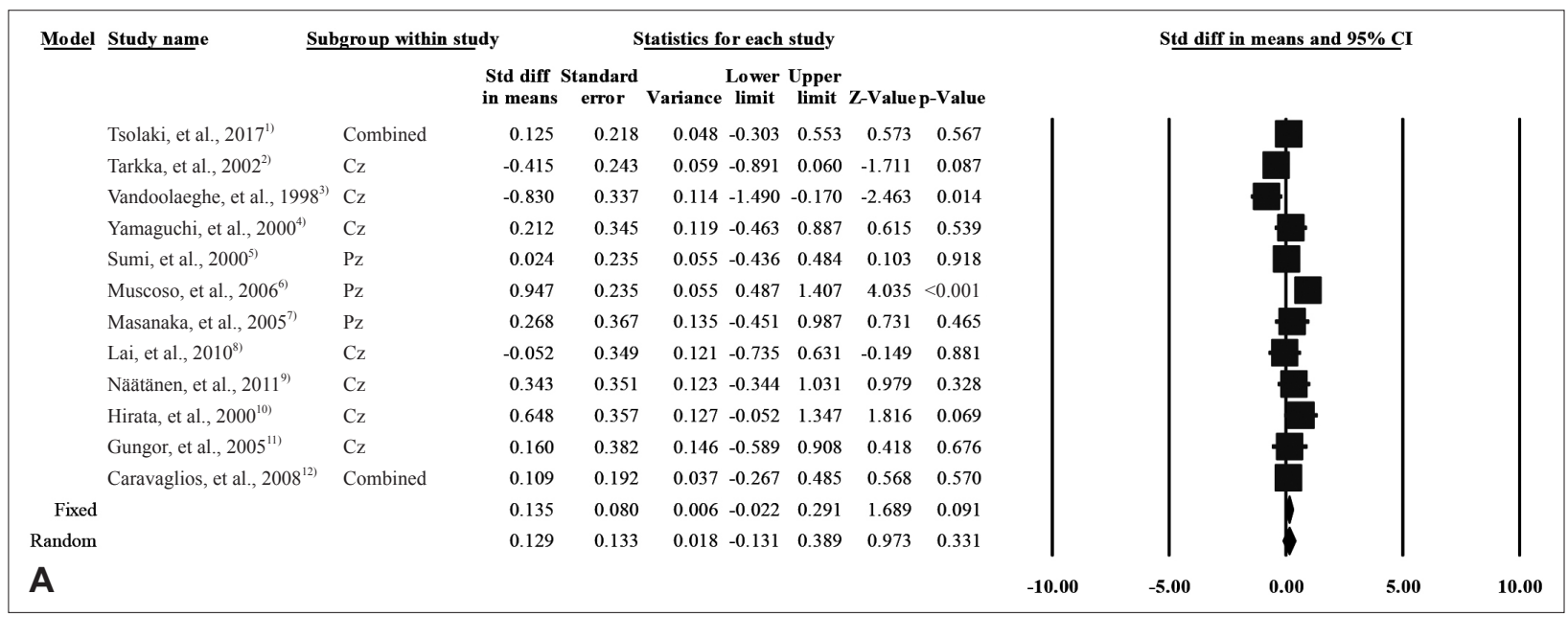

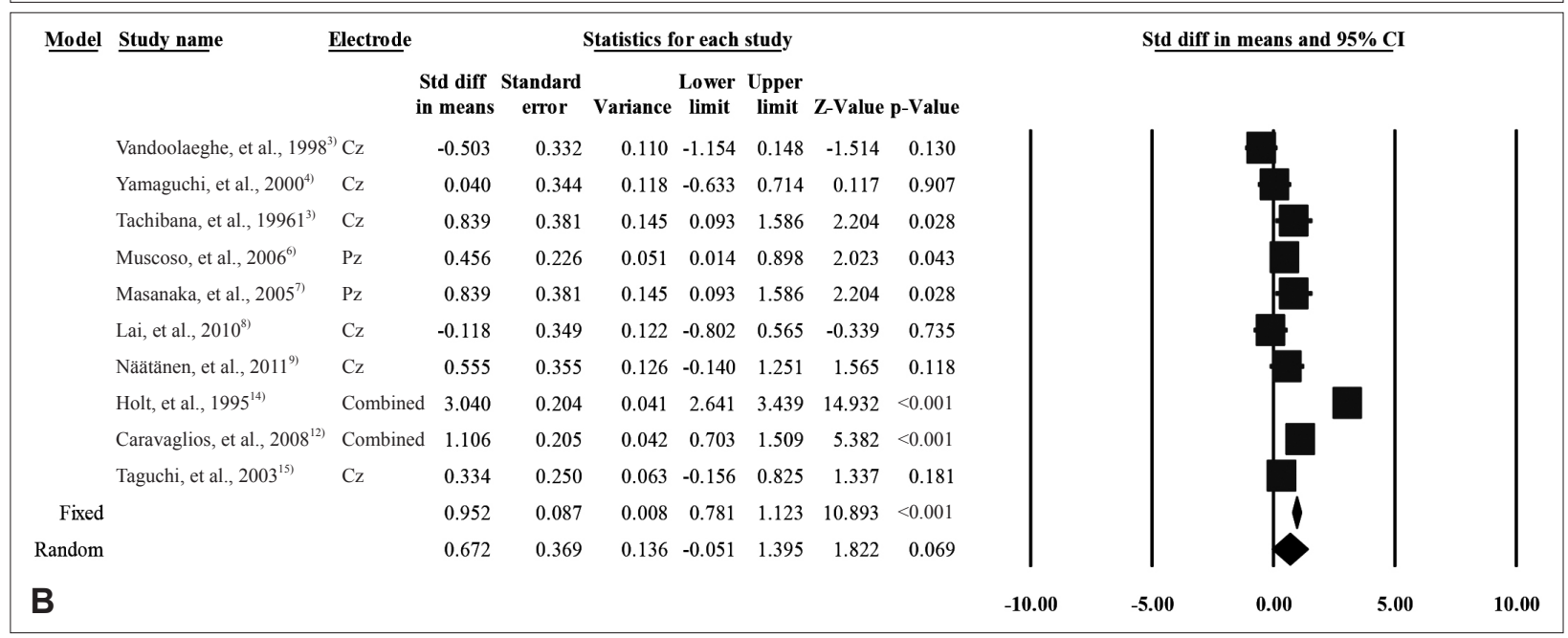

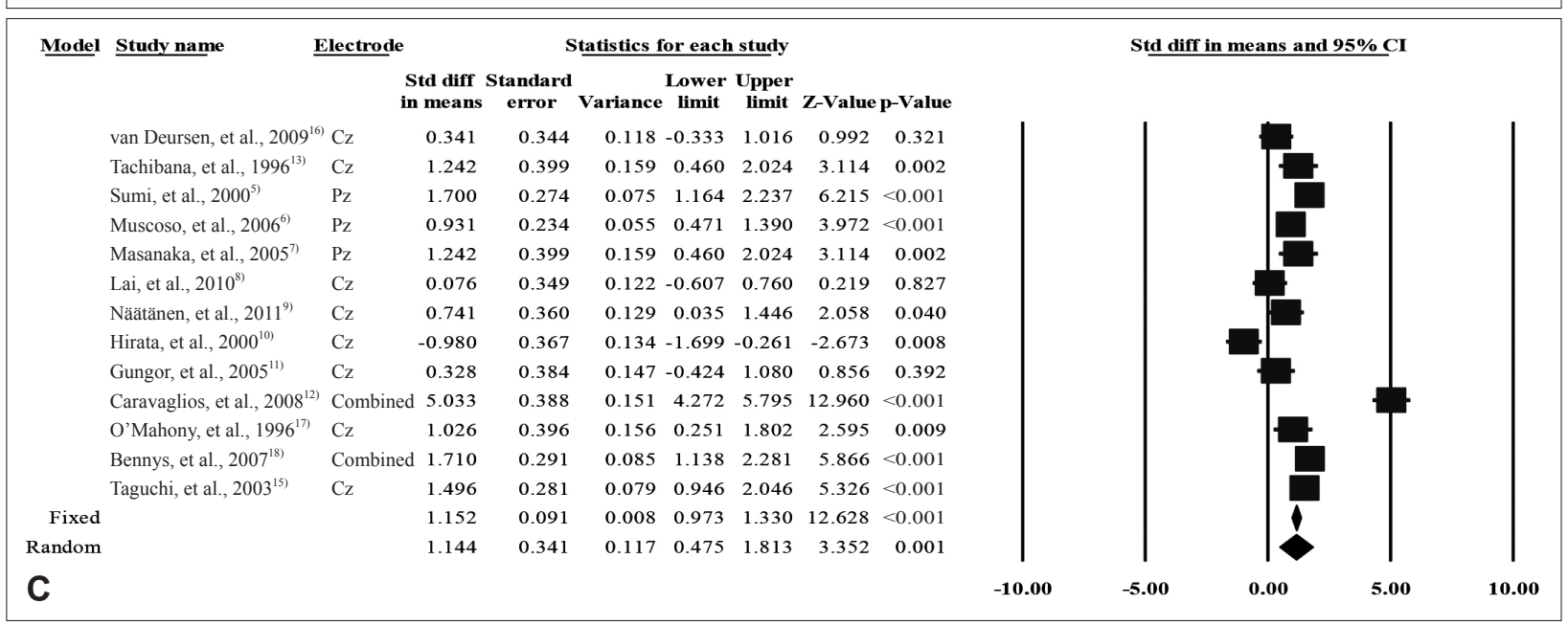




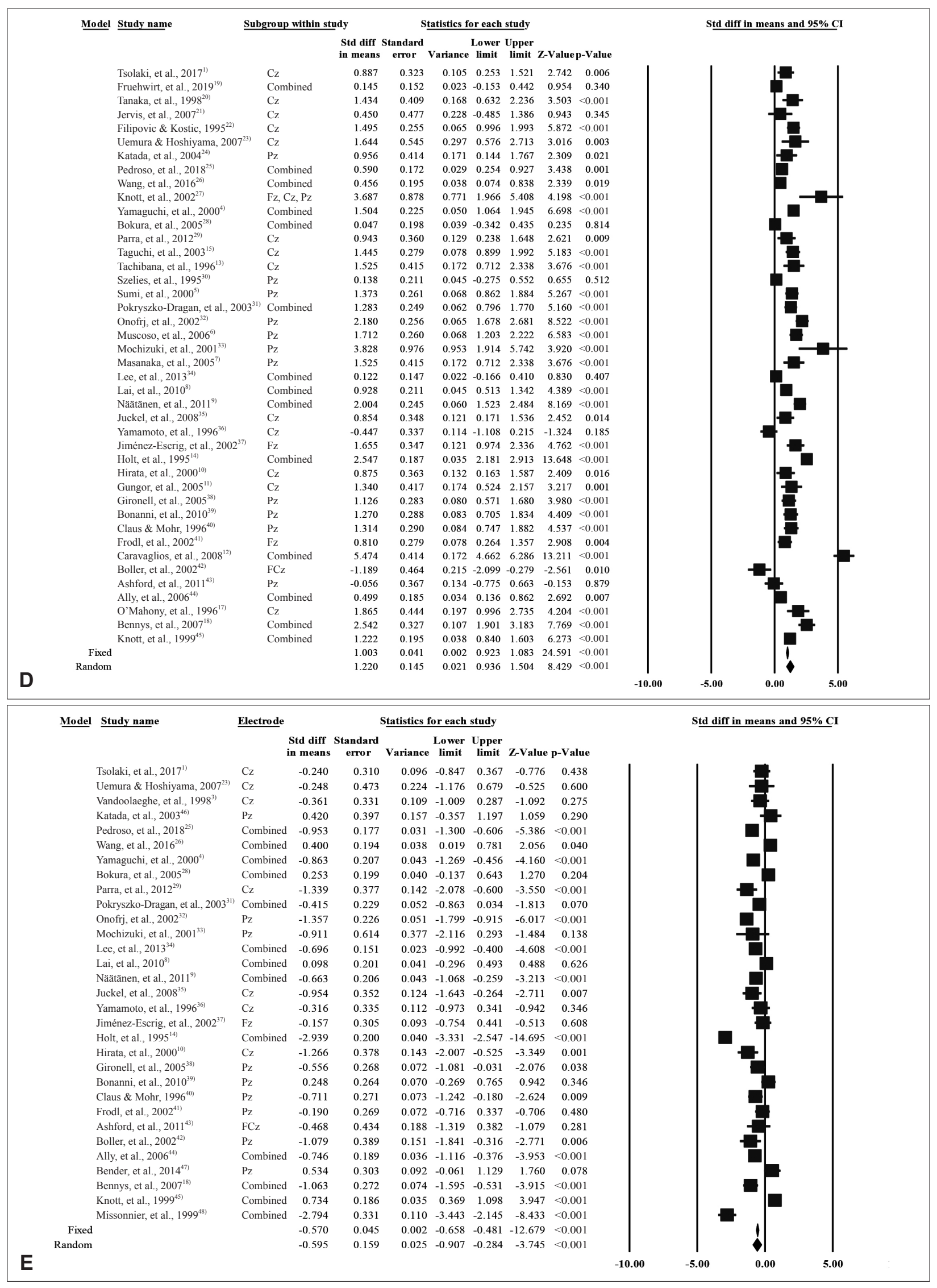




\section{Appendix 2}

The meta-analysis results for components of subjective measure

A: digit forward, B: digit backward, C: central auditory processing test, D: auditory word recall

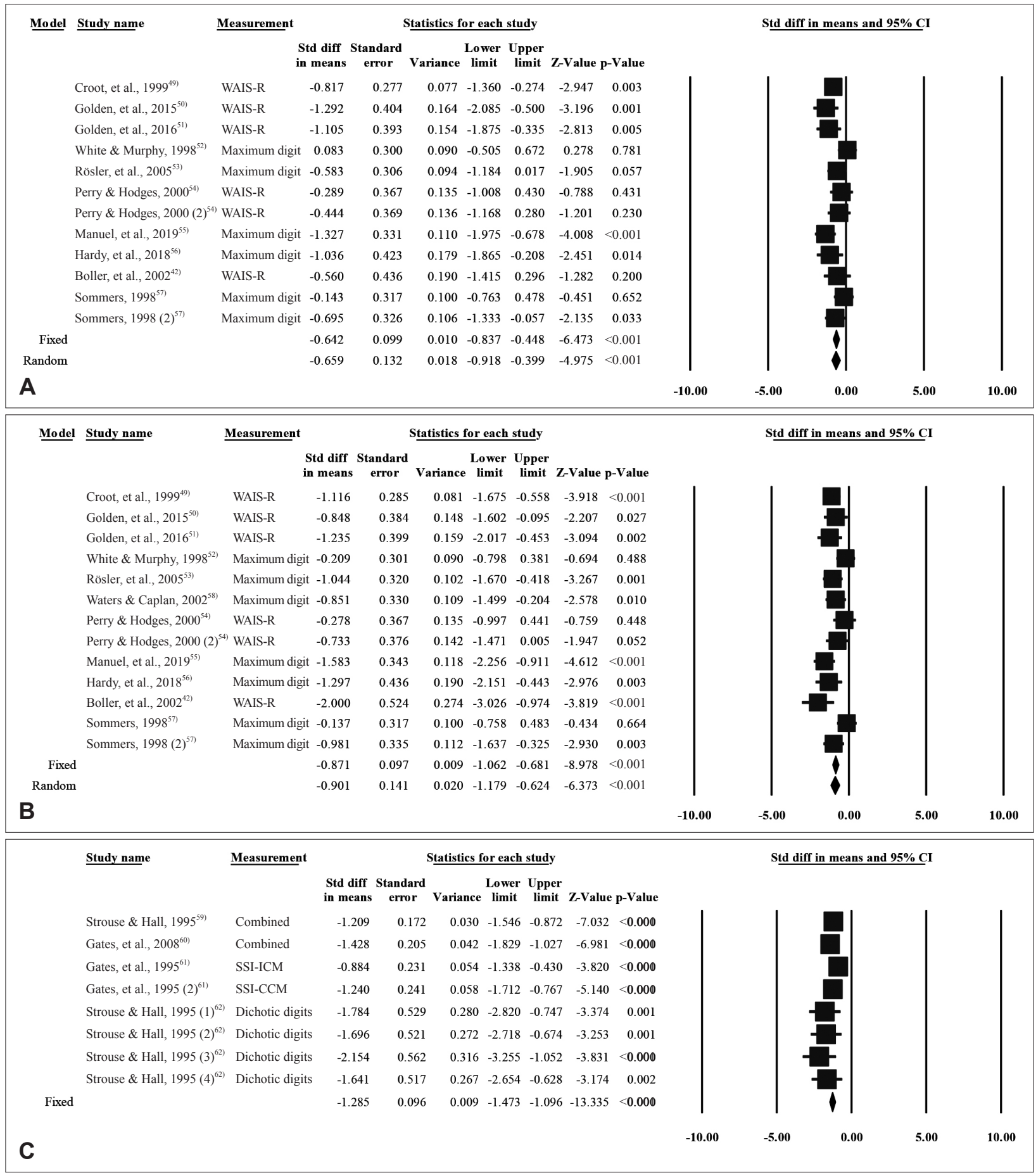


Korean J Otorhinolaryngol-Head Neck Surg I 2021;64(2):47-69

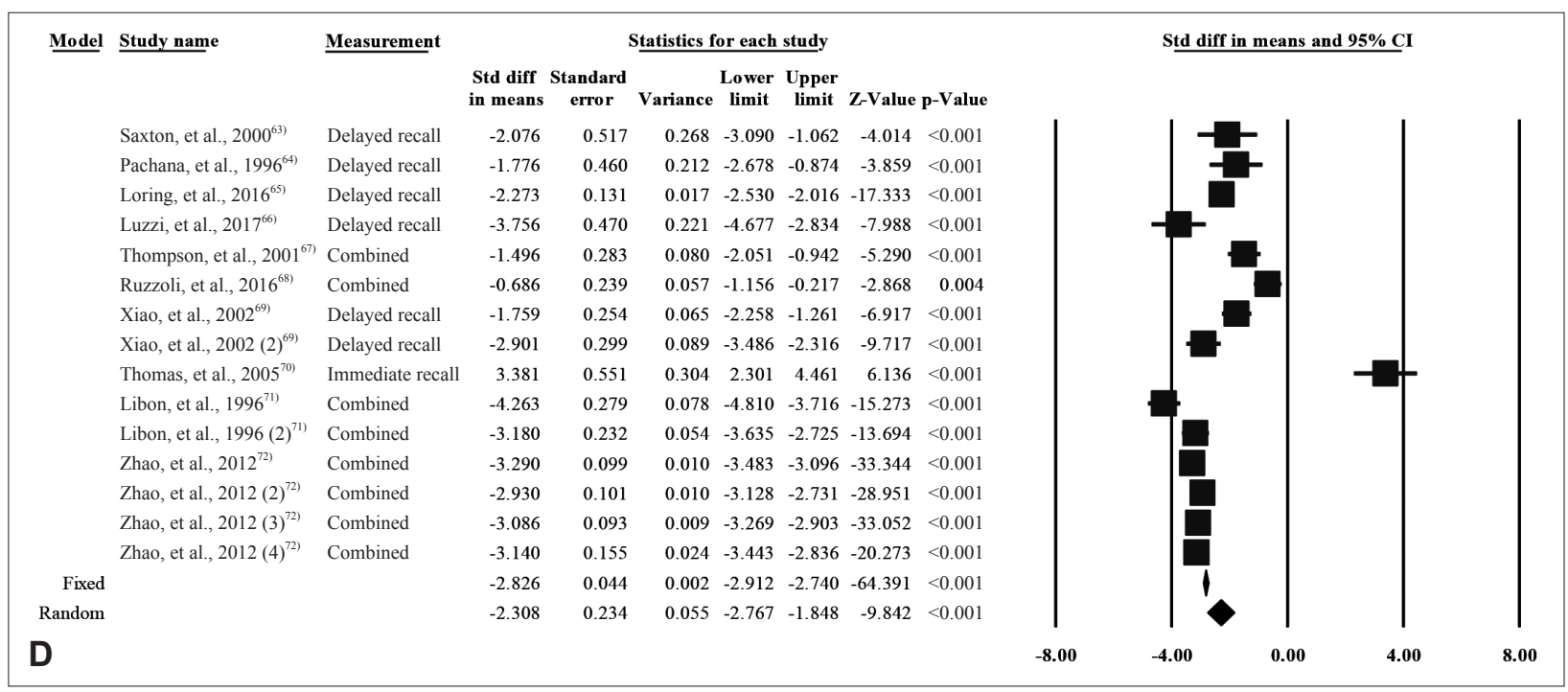




\title{
Appendix 3
}

\author{
72 articles which were used in the meta-analysis
}

1) Tsolaki AC, Kosmidou V, Kompatsiaris IY, Papadaniil C, Hadjileontiadis L, Adam A, et al. Brain source localization of MMN and P300 ERPs in mild cognitive impairment and Alzheimer's disease: A high-density EEG approach. Neurobiol Aging 2017;55:190-201.

2) Tarkka IM, Lehtovirta M, Soininen H, Pääkkönen A, Karhu J, Partanen J. Auditory adaptation is differentially impaired in familial and sporadic Alzheimer's disease. Biomed Pharmacother 2002;56(1):45-9.

3) Vandoolaeghe E, van Hunsel F, Nuyten D, Maes M. Auditory event related potentials in major depression: Prolonged P300 latency and increased P200 amplitude. J Affect Disord 1998;48(2-3):105-13.

4) Yamaguchi S, Tsuchiya H, Yamagata S, Toyoda G, Kobayashi S. Event-related brain potentials in response to novel sounds in dementia. Clin Neurophysiol 2000;111(2):195-203.

5) Sumi N, Nan'no H, Fujimoto O, Ohta Y, Takeda M. Interpeak latency of auditory event-related potentials (P300) in senile depression and dementia of the Alzheimer type. Psychiatry Clin Neurosci 2000;54(6):679-84.

6) Muscoso EG, Costanzo E, Daniele O, Maugeri D, Natale E, Caravaglios G. Auditory event-related potentials in subcortical vascular cognitive impairment and in Alzheimer's disease. J Neural Transm (Vienna) 2006;113(11):1779-86.

7) Masanaka T, Hisao T, Keita K, Yasunobu K, Hiroo Y, Bungo O. Multi-modal evoked potentials in corticobasal degeneration, progressive supranuclear palsy and Alzheimer disease. Int Congr 2005;1278:145-8.

8) Lai CL, Lin RT, Liou LM, Liu CK. The role of event-related potentials in cognitive decline in Alzheimer's disease. Clin Neurophysiol 2010; 121(2):194-9.

9) Näätänen R, Kujala T, Kreegipuu K, Carlson S, Escera C, Baldeweg T, et al. The mismatch negativity: an index of cognitive decline in neuropsychiatric and neurological diseases and in ageing. Brain 2011;134(12):3435-53.

10) Hirata K, Hozumi A, Tanaka H, Kubo J, Zeng XH, Yamazaki K, et al. Abnormal information processing in dementia of Alzheimer type. A study using the event-related potential's field. Eur Arch Psychiatry Clin Neurosci 2000;250(3):152-5.

11) Gungor HA, Yildiz A, Aydin F, Gungor F, Boz A, Ozkaynak S. Tc-99m HMPAO brain SPECT findings in mild and moderate Alzheimer's disease: Correlation with event related potentials. J Neurol Sci 2005;234(1-2):47-53.

12) Caravaglios G, Costanzo E, Palermo F, Muscoso EG. Decreased amplitude of auditory event-related delta responses in Alzheimer's disease. Int J Psychophysiol 2008;70(1):23-32.

13) Tachibana H, Takeda M, Okuda B, Kawabata K, Nishimura H, Kodama N, et al. Multimodal evoked potentials in Alzheimer's disease and Binswanger's disease. J Geriatr Psychiatry Neurol 1996;9(1):7-12.

14) Holt LE, Raine A, Pa G, Schneider LS, Henderson VW, Pollock VE. P300 topography in Alzheimer's disease. Psychophysiology 1995;32(3): 257-65.

15) Taguchi S, Fujimoto O, Takamori N, Hanatani T, Sumi N, Nan'no H, et al. Neurophysiological evaluation of late paraphrenia: Comparison with chronic schizophrenia and dementia of the Alzheimer type. Psychogeriatrics 2003;3(1):29-38.

16) van Deursen JA, Vuurman EF, Smits LL, Verhey FR, Riedel WJ. Response speed, contingent negative variation and P300 in Alzheimer's disease and MCI. Brain Cogn 2009;69(3):592-9.

17) O’Mahony D, Coffey J, Murphy J, O'Hare N, Hamilton D, Rowan M, et al. Event-related potential prolongation in Alzheimer's disease signifies frontal lobe impairment: Evidence from SPECT imaging. J Gerontol A Biol Sci Med Sci 1996;51(3):M102-7.

18) Bennys K, Portet F, Touchon J, Rondouin G. Diagnostic value of event-related evoked potentials N200 and P300 subcomponents in early diagnosis of Alzheimer's disease and mild cognitive impairment. J Clin Neurophysiol 2007;24(5):405-12.

19) Fruehwirt W, Dorffner G, Roberts S, Gerstgrasser M, Grossegger D, Schmidt R, et al. Associations of event-related brain potentials and Alzheimer's disease severity: A longitudinal study. Prog Neuropsychopharmacol Biol Psychiatry 2019;92:31-38.

20) Tanaka F, Kachi T, Yamada T, Sobue G. Auditory and visual event-related potentials and flash visual evoked potentials in Alzheimer's disease: Correlations with Mini-Mental State Examination and Raven's Coloured Progressive Matrices. J Neurol Sci 1998;156(1):83-8.

21) Jervis B, Belal S, Camilleri K, Cassar T, Bigan C, Linden DE, et al. The independent components of auditory P300 and CNV evoked potentials derived from single-trial recordings. Physiol Meas 2007;28(8):745-71.

22) Filipović SR, Kostić VS. Utility of auditory P300 in detection of presenile dementia. J Neurol Sci 1995;131(2):150-5.

23) Uemura JI, Hoshiyama M. Variability of P300 in elderly patients with dementia during a single day. Int J Rehabil Res 2007;30(2):167-70.

24) Katada E, Sato K, Ojika K, Ueda R. Cognitive event-related potentials: Useful clinical information in Alzheimer's disease. Current Alzheimer Research 2004;1(1):63-9.

25) Pedroso RV, Cancela JM, Ayán C, Stein AM, Fuzaro G, Costa JLR, et al. Effects of physical exercise on the P300 of elderly with Alzheimer's disease. J Phys Act Health 2018;15(6):403-10.

26) Wang P, Zhang H, Han L, Zhou Y. Cortical function in Alzheimer's disease and frontotemporal dementia. Transl Neurosci 2016;7(1):116-25.

27) Knott V, Mohr E, Mahoney C, Engeland C, Ilivitsky V. Effects of acute nicotine administration on cognitive event-related potentials in tacrinetreated and non-treated patients with Alzheimer's disease. Neuropsychobiology 2002;45(3):156-60.

28) Bokura H, Yamaguchi S, Kobayashi S. Event-related potentials for response inhibition in Parkinson's disease. Neuropsychologia 2005;43(6): 967-75.

29) Parra MA, Ascencio LL, Urquina HF, Manes F, Ibáñez AM. P300 and neuropsychological assessment in mild cognitive impairment and Alzheimer dementia. Front Neurol 2012;3:172.

30) Szelies B, Mielke R, Grond M, Heiss WD. P300 in Alzheimer's disease: Relationships to dementia severity and glucose metabolism. J Neurol Sci 1995;130(1):77-81.

31) Pokryszko-Dragan A, Słotwiński K, Podemski R. Modality-specific changes in P300 parameters in patients with dementia of the Alzheimer 
type. Med Sci Monit 2003;9(4):CR130-4.

32) Onofrj M, Thomas A, Luciano AL, Iacono D, Di Rollo A, D’Andreamatteo G, et al. Donepezil versus vitamin E in Alzheimer's disease: Part 2: mild versus moderate-severe Alzheimer's disease. Clin Neuropharmacol 2002;25(4):207-15.

33) Mochizuki Y, Oishi M, Takasu T. Correlations between P300 components and regional cerebral blood flows. J Clin Neurosci 2001;8(5):407-10.

34) Lee MS, Lee SH, Moon EO, Moon YJ, Kim S, Kim SH, et al. Neuropsychological correlates of the P300 in patients with Alzheimer's disease. Prog Neuropsychopharmacol Biol Psychiatry 2013;40:62-9.

35) Juckel G, Clotz F, Frodl T, Kawohl W, Hampel H, Pogarell O, et al. Diagnostic usefulness of cognitive auditory event-related p300 subcomponents in patients with Alzheimers disease? J Clin Neurophysiol 2008;25(3):147-52.

36) Yamamoto M, Kachi T, Igata A. Pain-related somatosensory evoked potentials in dementia. J Neurol Sci 1996;137(2):117-9.

37) Jiménez-Escrig A, Fernandez-Lorente J, Herrero A, Baron M, Lousa M, de Blas G, et al. Event-related evoked potential P300 in frontotemporal dementia. Dement Geriatr Cogn Disord 2002;13(1):27-32.

38) Gironell A, García-Sánchez C, Estévez-González A, Boltes A, Kulisevsky J. Usefulness of p300 in subjective memory complaints: A prospective study. J Clin Neurophysiol 2005;22(4):279-84.

39) Bonanni L, Franciotti R, Onofrj V, Anzellotti F, Mancino E, Monaco D, et al. Revisiting P300 cognitive studies for dementia diagnosis: Early dementia with Lewy bodies (DLB) and Alzheimer disease (AD). Neurophysiol Clin 2010;40(5-6):255-65.

40) Claus JJ, Mohr E. Attentional deficits in Alzheimer's, Parkinson's, and Huntington's diseases. Acta Neurol Scand 1996;93(5):346-51.

41) Frodl T, Hampel H, Juckel G, Bürger K, Padberg F, Engel RR, et al. Value of event-related P300 subcomponents in the clinical diagnosis of mild cognitive impairment and Alzheimer's disease. Psychophysiology 2002;39(2):175-81.

42) Boller F, El Massioui F, Devouche E, Traykov L, Pomati S, Starkstein SE. Processing emotional information in Alzheimer's disease: Effects on memory performance and neurophysiological correlates. Dement Geriatr Cogn Disord 2002;14(2):104-12.

43) Ashford JW, Coburn KL, Rose TL, Bayley PJ. P300 energy loss in aging and Alzheimer's disease. J Alzheimers Dis 2011;26 Suppl 3:229-38.

44) Ally BA, Jones GE, Cole JA, Budson AE. The P300 component in patients with Alzheimer's disease and their biological children. Biol Psychol 2006;72(2):180-7.

45) Knott V, Mohr E, Haché N, Mahoney C, Mendis T. EEG and the passive P300 in dementia of the Alzheimer type. Clin Electroencephalogr 1999;30(2):64-72.

46) Katada E, Sato K, Sawaki A, Dohi Y, Ueda R, Ojika K. Long-term effects of donepezil on P300 auditory event-related potentials in patients with Alzheimer's disease. J Geriatr Psychiatry Neurol 2003;16(1):39-43.

47) Bender S, Bluschke A, Dippel G, Rupp A, Weisbrod M, Thomas C. Auditory post-processing in a passive listening task is deficient in Alzheimer's disease. Clin Neurophysiol 2014;125(1):53-62.

48) Missonnier P, Ragot R, Derouesné C, Guez D, Renault B. Automatic attentional shifts induced by a noradrenergic drug in Alzheimer's disease: Evidence from evoked potentials. Int J Psychophysiol 1999;33(3):243-51.

49) Croot K, Hodges JR, Patterson K. Evidence for impaired sentence comprehension in early Alzheimer's disease. J Int Neuropsychol Soc 1999; 5(5):393-404

50) Golden HL, Agustus JL, Goll JC, Downey LE, Mummery CJ, Schott JM, et al. Functional neuroanatomy of auditory scene analysis in Alzheimer's disease. Neuroimage Clin 2015;7:699-708.

51) Golden HL, Agustus JL, Nicholas JM, Schott JM, Crutch SJ, Mancini L, et al. Functional neuroanatomy of spatial sound processing in Alzheimer's disease. Neurobiol Aging 2016;39:154-64.

52) White DA, Murphy CF. Working memory for nonverbal auditory information in dementia of the Alzheimer type. Arch Clin Neuropsychol 1998;13(4):339-47.

53) Rösler A, Mapstone M, Hays-Wicklund A, Gitelman DR, Weintraub S. The "zoom lens" of focal attention in visual search: Changes in aging and Alzheimer's disease. Cortex 2005;41(4):512-9.

54) Perry RJ, Hodges JR. Fate of patients with questionable (very mild) Alzheimer's disease: Longitudinal profiles of individual subjects' decline. Dement Geriatr Cogn Disord 2000;11(6):342-9.

55) Manuel AL, Foxe D, Bradshaw N, Cordato NJ, Hodges JR, Burrell JR, et al. Sustained attention failures on a 3-min reaction time task is a sensitive marker of dementia. J Neurol 2019;266(6):1323-31.

56) Hardy CJD, Marshall CR, Bond RL, Russell LL, Dick K, Ariti C, et al. Retained capacity for perceptual learning of degraded speech in primary progressive aphasia and Alzheimer's disease. Alzheimers Res Ther 2018;10(1):70.

57) Sommers MS. Spoken word recognition in individuals with dementia of the Alzheimer's type: Changes in talker normalization and lexical discrimination. Psychol Aging 1998;13(4):631-46.

58) Waters G, Caplan D. Working memory and online syntactic processing in Alzheimer's disease: Studies with auditory moving window presentation. J Gerontol B Psychol Sci Soc Sci 2002;57(4):P298-311.

59) Strouse AL, Hall JW 3rd. Test-retest reliability of a dichotic digits test for assessing central auditory function in Alzheimer's disease. Audiology 1995;34(2):85-90.

60) Gates GA, Anderson ML, Feeney MP, McCurry SM, Larson EB. Central auditory dysfunction in older persons with memory impairment or Alzheimer dementia. Archives of Otolaryngology-Head \& Neck Surgery 2008;134(7):771-7.

61) Gates GA, Karzon RK, Garcia P, Peterein J, Storandt M, Morris JC, et al. Auditory dysfunction in aging and senile dementia of the Alzheimer's type. Arch Neurol 1995;52(6):626-34.

62) Strouse AL, Hall JW 3rd, Burger MC. Central auditory processing in Alzheimer's disease. Ear Hear 1995;16(2):230-8.

63) Saxton J, Munro CA, Butters MA, Schramke C, McNeil MA. Alcohol, dementia, and Alzheimer's disease: Comparison of neuropsychological profiles. J Geriatr Psychiatry Neurol 2000;13(3):141-9.

64) Pachana NA, Boone KB, Miller BL, Cummings JL, Berman N. Comparison of neuropsychological functioning in Alzheimer's disease and frontotemporal dementia. J Int Neuropsychol Soc 1996;2(6):505-10.

65) Loring DW, Goldstein FC, Chen C, Drane DL, Lah JJ, Zhao L, et al. False-positive error rates for reliable digit span and auditory verbal learning test performance validity measures in amnestic mild cognitive impairment and early Alzheimer disease. Arch Clin Neuropsychol 
2016;31(4):313-31.

66) Luzzi S, Baldinelli S, Ranaldi V, Fabi K, Cafazzo V, Fringuelli F, et al. Famous faces and voices: Differential profiles in early right and left semantic dementia and in Alzheimer's disease. Neuropsychologia 2017;94:118-28.

67) Thompson SB, Macdonald J, Coates TD. Improving visual memory with Aricept (donepezil hydrochloride, E2020) in mild-to-moderate Alzheimer's disease. Clin Gerontol 2001;24(1-2):55-73.

68) Ruzzoli M, Pirulli C, Mazza V, Miniussi C, Brignani D. The mismatch negativity as an index of cognitive decline for the early detection of Alzheimer's disease. Sci Rep 2016;6:33167.

69) Xiao S, Yao P, Li X, Zhang M. Neuropsychological testing profiles of patients with Alzheimer's disease and mild cognitive impairment: A case-control study. Hong Kong J Psychiatry 2002;12(4):2-5.

70) Thomas DA, Libon DJ, Ledakis GE. Treating dementia patients with vascular lesions with donepezil: A preliminary analysis. Appl Neuropsychol 2005;12(1):12-8.

71) Libon DJ, Mattson RE, Glosser G, Kaplan E, Malamut BL, Sands LP, et al. A nine-word dementia version of the California verbal learning test. Clin Neuropsychol 1996:10(3):237-44.

72) Zhao Q, Lv Y, Zhou Y, Hong Z, Guo Q. Short-term delayed recall of auditory verbal learning test is equivalent to long-term delayed recall for identifying amnestic mild cognitive impairment. PLoS One 2012;7(12):e51157.

\section{정답 및 해설}

답 (4)

해 설 증례는 전두동에 발생한 골종으로 부비동에서 가장 흔히 발견되는 양성종양이다.

참고 문헌: 대한이비인후과학회. 이비인후과학:비과. 개정2판. 파주: 군자출판사;2018. p.544-5. 